Elsevier Editorial System(tm) for Tribology International

Manuscript Draft

Manuscript Number: TRIBINT-D-14-00933

Title: ELECTROMECHANICAL INTERACTION BETWEEN CARBON BASED PANTOGRAPH STRIP AND COPPER CONTACT WIRE: A HEURISTIC WEAR MODEL

Article Type: Full Length Article

Keywords: pantograph-catenary interaction; Kasperovski contact strip; pure copper contact wire; dynamics of the electromechanical sliding contact.

Corresponding Author: Dr. Giuseppe Bucca, Ph.D.

Corresponding Author's Institution: Politecnico di Milano

First Author: Giuseppe Bucca, Ph.D.

Order of Authors: Giuseppe Bucca, Ph.D.; Andrea Collina, Full Professor

Abstract: Main contributions to the wear in the sliding contact between pantograph's strip and catenary's wire can be classified as: i) mechanical contribution, due to friction, ii) electrical contribution, due to current flow at the contact and iii) electrical arcs contribution related to power dissipated during arc generation. In this work, a heuristic wear model for the contact wire, which accounts for the mentioned three main contributions to the wear, is presented. After a tuning phase with results obtained by an experimental campaign aimed at evaluating the wear for the couple "pure copper contact wire - Kasperovski contact strip", the wear model is used in combination with a dynamical electromechanical model able to reproduce the electromechanical pantograph-catenary interaction.

Suggested Reviewers: Takayuki Usuda

Railway Technical Research Institute

usuda@rtri.or.jp

Dr Usuda is senior researcher on the interaction between pantograph and catenary and on related problems.

Rafael Manory

M\&H Materials Pty Ltd

rmanory@kuee.kyoto-u.ac.jp

Dr Manory studies problems related to the interaction between pantograph and catenary, to the sliding wear, to the electromechanical contacts and to the wear tests for copper and graphite materials.

Guangxiong Chen

Southwest Jiaotong University, State Key Laboratory of Traction Power, Chengdu, China chen_guangx@163.com

Author of different works on electromechanical problems related to pantograph-catenary interaction. 
Dear Tribology International Editors,

we would like to submit the present paper titled " Electromechanical interaction between carbon based pantograph strip and copper contact wire: a heuristic wear model" for a possible publication on your review.

The paper deals with a heuristic wear model, tuned using results obtained by a laboratory campaign on the couple "pure copper contact wire - Kasperovski contact strip", which is used in combination with a dynamical electromechanical model able to reproduce the electromechanical pantographcatenary interaction. This procedure try to reproduce the real conditions that cause the wire's wear evolution.

The practical application of the presented procedure can be useful to estimate the maintenance costs related to the wear of contact wire and to assess the effective benefit of proposed innovative solutions for pantographs and catenaries.

Best Regards, Giuseppe Bucca, Andrea Collina

giuseppe.bucca@polimi.it 
I confirm that this paper is original and it has not been published previously and it is not under consideration elsewhere.

Giuseppe Bucca, on behalf of all authors 
Main contributions to the wear in the sliding contact between pantograph's strip and catenary's wire can be classified as: i) mechanical contribution, due to friction, ii) electrical contribution, due to current flow at the contact and iii) electrical arcs contribution related to power dissipated during arc generation. In this work, a heuristic wear model for the contact wire, which accounts for the three main contributions to the wear, is presented. A laboratory campaign on the couple "pure copper contact wire - Kasperovski contact strip" allows us to tune the heuristic wear model, which is used in combination with a dynamical electromechanical model able to reproduce the electromechanical pantograph-catenary interaction. The aim of this procedure is to reproduce the real conditions that cause the wire's wear evolution.

The application of the presented procedure can be useful to estimate the maintenance costs related to the wear of contact wire and to assess the effective benefit of proposed innovative solutions for pantographs and catenaries. 


\title{
ELECTROMECHANICAL INTERACTION BETWEEN CARBON BASED PANTOGRAPH STRIP AND COPPER CONTACT WIRE: A HEURISTIC WEAR MODEL
}

\author{
Giuseppe Bucca", Andrea Collina \\ Department of Mechanical Engineering, Politecnico di Milano \\ Via La Masa 1, 20156 Milano - ITALY
}

\begin{abstract}
Main contributions to the wear in the sliding contact between pantograph's strip and catenary's wire can be classified as: i) mechanical contribution, due to friction, ii) electrical contribution, due to current flow at the contact and iii) electrical arcs contribution related to power dissipated during arc generation. In this work, a heuristic wear model for the contact wire, which accounts for the mentioned three main contributions to the wear, is presented. After a tuning phase with results obtained by an experimental campaign aimed at evaluating the wear for the couple "pure copper contact wire - Kasperovski contact strip", the wear model is used in combination with a dynamical electromechanical model able to reproduce the electromechanical pantograph-catenary interaction.
\end{abstract}

Keywords: pantograph-catenary interaction, Kasperovski contact strip, pure copper contact wire, dynamics of the electromechanical sliding contact.

\footnotetext{
"Corresponding author:

E-mail: giuseppe.bucca@polimi.it; Tel: +39 022399 8496; Fax: +39 0223998492.
} 


\section{Introduction}

The sliding contact between the pantograph contact strip and the catenary contact wire is characterised by electromechanical phenomena that influence the tribological behaviour of the two contacting bodies. These electromechanical phenomena cause wear on both strip and wire, influencing the maintenance costs either of rolling stock or of infrastructure. Investigations have been and are being carried out ([1-17]) concerning the wear behaviour during strip and wire interaction and the development of materials for both strip and wire in order to enable the current collection keeping acceptable wear rate of the two contacting elements.

Nowadays, the railway research is mainly devoted to study the improvements of rolling stock and infrastructure needed to increase the railway operation speed and capacity. One consequence of the railway vehicle speed is the unavoidable increase of the electrical current value that has to be collected: for d.c. (direct current) railway high-speed line the electrical current value per strip can be up to $1400 \mathrm{~A}$. These conditions are obviously rather severe for the interacting couple strip - wire and studies are being carried out to assure acceptable wear rates.

The experience on the electromechanical interaction between pantograph and catenary leads to affirm that the main contributions to the wear rate of strip and wire are three: i) the mechanical contribution, due to the frictional power dissipation; ii) the electrical contribution, due to power dissipation related to the current flow at the contact (Joule effect) ; iii) the electrical arcs contribution, due to the power dissipation generated by the electrical arcs that occur when the contact dynamics causes a contact loss. These three contributions are not independent but they are strictly interacting among them. Moreover, the analysis of the wear mechanisms typical of the electromechanical sliding contact between strip and wire has to consider the complex tribological condition, which is characterized by high values of sliding 
speed (up to about $80 \mathrm{~m} / \mathrm{s}$ ) and high values of electrical current. This contact condition produces high levels of heat on the contact zone and on the strip. For the typical strip used in the railway operation, which are carbon based, the heat generation at the contact is mainly related to the passage of electrical current at the contact area because of the low value of the frictional power dissipation. Due to the complexity of the wear phenomena, the only possible way to develop wear models is the use of experimental test results. The wear rate can be related to the effects of the operative parameters, as the sliding speed, the electrical current, the contact force and, obviously, the material characteristics of the contacting bodies.

One of the most important reason to develop a wear model is to estimate the wear rate during certain conditions of the railway operation in order to assess, generally in the design stage, benefit produced by particular solutions especially in terms of reduction of maintenance costs. In this work, a heuristic wear model for the contact wire, which accounts for the three main contributions to the wear, is presented. This wear model has been tuned by means of the results obtained by a laboratory experimental campaign carried out to evaluate the electromechanical wear for the couple "electrolytic copper (Cu-ETP or pure copper) contact wire - Kasperovski contact strip". In particular, the Kasperovski contact strip (Figure 1) is a contact strip with the carbon part encased in the copper part on three sides. The width of the tested Kasperovski strip is $65 \mathrm{~mm}$ while the thickness of the copper sides is $3 \mathrm{~mm}$ (see Figure 1b).

\section{FIGURE 1 TO APPEAR HERE}

The wear model has been developed for the use in combination with a dynamical electromechanical model able to reproduce the electromechanical interaction between the 
pantograph and the catenary. In this way, the instantaneous values of the contact forces and of the electrical current obtained by the dynamical simulation of the electromechanical model are fed into the wear model and the amount of the wear for the contact wire is evaluated. This procedure aims at reproducing the real conditions that cause the wear evolution of the contact wire: in effect, in the real operation, the dynamics of the electromechanical interaction between pantograph and catenary heavily influences the wear rate of contacting bodies.

The paper is organized as follows: after a description of the test rig used for the experimental tests and an analysis of experimental results (section 2), in section 3 the wear model is introduced and tuned by means of the experimental results described in section 2 . In section 4 the electromechanical model for the simulation of the dynamical interaction between pantograph and catenary is discussed. Finally, in section 5 an application of the procedure to evaluate the contact wire's wear evolution with different wire irregularity conditions is presented and the related results are discussed.

\section{The laboratory experimental campaign}

The wear behaviour of the strip-wire couple can be analysed by means of experimental tests. In particular, in this work the couple "electrolytic copper (Cu-ETP or pure copper) contact wire - Kasperovski contact strip" during direct current (d.c.) collection is considered. In this section, the test rig used for the wear tests is described and the obtained results are discussed.

\subsection{The test rig}

The test rig used for the experimental tests reported in this work has been developed by the researchers of the Department of Mechanical Engineering of Politecnico di Milano ([11-13]). It enables the testing of a full-scale contact strip with the following test parameters:

- $\quad$ sliding speed between strip and wire up to $220 \mathrm{~km} / \mathrm{h}$; 
- level of electrical current flowing between strip and wire up to $1400 \mathrm{~A}$ in d.c., $500 \mathrm{~A}$ in a.c. (alternate current) $16_{2 / 3} \mathrm{~Hz}$ and $350 \mathrm{~A}$ in a.c. $50 \mathrm{~Hz}$, in order to reproduce the typical European railway power supply;

- vertical static preload between strip and wire up to $120 \mathrm{~N}$.

\section{FIGURE 2 TO APPEAR HERE}

The test rig is composed of a fibre-glass wheel, with a $2.2 \mathrm{~m}$ radius, rotating around a vertical axis, with a contact wire elastically connected along its perimeter by means of 36 flexible supports (Figure 2). The collector strip is mounted on two suspensions connected to a platform driven with a controlled motion by an a.c. brushless motor along the radial direction of the wheel, in order to reproduce the relative motion due to staggering of the contact wire (zig-zag motion). For this aim, the platform radial motion follows a triangular wave signal and the platform radial speed is synchronized with the test speed. The combination of the peripheral speed of the wheel, which reproduces the train speed, and the transversal motion imposed to the strip represents the composed longitudinal and transversal sliding contact between the wire and the strip. A ventilation apparatus, which conveys an air flow on the strip-wire contact zone, at the same speed of the test is also present, enables to reproduce the thermal condition in the contact area, which heavily affects the performance of the strip material. The contact force between the collector and the contact wire is applied by means of a hydraulic actuator mounted on the moving platform. A three-phase full-bridge rectifier with capacitors feeds an IGBT converter, which is able to reproduce the typical European railway power supply: direct current and alternate current $\left(50 \mathrm{~Hz}\right.$ and $\left.16_{2 / 3} \mathrm{~Hz}\right)$. 


\section{FIGURE 3 TO APPEAR HERE}

The test rig has a measurement set up able to monitor the test operating condition. In particular, the vertical and longitudinal components of the contact force are measured using two couples of load cells (Figure 3). The measurement of these two components of the contact force allows to calculate the friction coefficient. The contact strip temperature is measured by means of a thermocouple placed in the centre of the contact strip, in the carbon-copper interface. The vertical acceleration of contact strip is measured by means of one accelerometer placed on the centre of the contact strip, to verify the contact quality from the mechanical point of view. Moreover, the electrical current and the voltage at the contact are measured. In particular, the latter measurement is used to detect the contact loss and, consequently, the occurrence of the electrical arcs: a sudden increase of the voltage is related to the increase of the electrical contact resistance during the contact loss.

\section{FIGURE 4 TO APPEAR HERE}

The wear rate of the strip is estimated from the strip mass difference before and after the test, while the wear rate of the contact wire is estimated by the difference of the thickness between the end and the beginning of the test. The mass of the contact strip is measured by means of a digital balance able to measure weight variation of $0.1 \mathrm{~g}$, while the thickness of the contact wire is measured in selected 180 (5x36 supports) sections along the wire (Figure 4) by means of a laser system whose composed uncertainty is $3 \mu \mathrm{m}$. 


\subsection{The laboratory test results}

The wear tests aim at studying the wear behaviour of the interacting couple strip - wire for different operation parameters, i.e. speed, electrical current and static preload. For this reason, two levels of sliding speed $(160 \mathrm{~km} / \mathrm{h}$ and $200 \mathrm{~km} / \mathrm{h})$, two levels of static preload equal to $60 \mathrm{~N}$ and $90 \mathrm{~N}$ and six levels of electrical current $(0 \mathrm{~A}, 100 \mathrm{~A}, 200 \mathrm{~A}, 300 \mathrm{~A}, 750 \mathrm{~A}$ and 1000 A) were considered in order to deeply investigate the wear mechanism. Moreover, for the test at $200 \mathrm{~km} / \mathrm{h}, 90 \mathrm{~N}$ and $1000 \mathrm{~A}$, the effect of the addition of a dynamical force component was studied: in particular, a test where a sinusoidal variable component with a frequency equal to the frequency of the passage of pantograph under suspension at the test speed for a span length of $60 \mathrm{~m}$ was added to the static preload was carried out. The frequency of the dynamical component for the speed equal to $200 \mathrm{~km} / \mathrm{h}$ is $0.93 \mathrm{~Hz}$. Being the width of the strip equal to $65 \mathrm{~mm}$, the linear density of current (an usual parameter adopted in the railway field) ranges from $0 \mathrm{~A} / \mathrm{mm}$ to $15 \mathrm{~A} / \mathrm{mm}$. The total number of tests is 18 and the test sequence is reported in Table 1 . Some test conditions were repeated, as the test with the static preload equal to $90 \mathrm{~N}$, electrical current equal to $1000 \mathrm{~A}$ and sliding speed equal to $200 \mathrm{~km} / \mathrm{h}$, in order to verify the repeatability of the results. All tests were performed using Kasperovski contact strips and pure copper contact wire. The following figures report the main wear results in terms of NWR (Normal Wear Rate) index, defined as the ratio between the worn volume $\left(\mathrm{mm}^{3}\right)$ and the sliding distance $(\mathrm{km})$ :

$N W R=\frac{\text { Vol }_{\text {worn }}}{s}$

TABLE 1 TO APPEAR HERE 
FIGURE 5 TO APPEAR HERE

FIGURE 6 TO APPEAR HERE

The analysis of experimental results, reported in Figure 5 and 6 in terms of NWR as a function of electrical current, shows two different wear regimes for both the contact strip and the contact wire. For low values of electrical current (up to $200 \mathrm{~A}$ ) the wear rate for both contact wire and contact strip is extremely low, while for electrical current value beyond 300 A the wear rate increases. This phenomenon can be explained considering that the low values of electrical current don't produce the conditions able to cause the typical wear mechanisms on the strip-wire contact with high electrical current passage ("oxidative wear" and "melt wear" ([10-11]).

Analysing Figure 5, it is possible to notice that, for electrical current greater than $200 \mathrm{~A}$, the contact strip presents a wear rate index increasing with the current, almost independently from the mean contact force. Moreover, for the tests carried out with an electrical current level of $1000 \mathrm{~A}$, it is possible to analyse the effect of the speed value and of the dynamic contribution of contact force on the wear rate of contact strip. The increase of speed from $160 \mathrm{~km} / \mathrm{h}$ to $200 \mathrm{~km} / \mathrm{h}$ produces an increase in the NWR of contact strip of about $15 \%$ on average. This behaviour can be explained considering that an increase of sliding speed produces an increase of the mechanical contribution to the wear (the power dissipation due to the friction is proportional to the sliding speed) but it also causes an increase of the contact force variation due to the dynamics of the interaction between contact strip and contact wire. In this last condition, i.e. for the speed value of $200 \mathrm{~km} / \mathrm{h}$, the occurrence of contact loss, and then the 
occurrence of electrical arc generation, is higher than the case in which the speed value is equal to $160 \mathrm{~km} / \mathrm{h}$ and consequently also the NWR of the strip will result higher for a high value of speed.

The analysis of Figure 6 allows to point out a dependence on the contact force of NWR of the contact wire for electrical current greater than $200 \mathrm{~A}$. The most evident result is that the highest wear rate for the contact wire is obtained when the electrical current value is equal to $300 \mathrm{~A}$ and the static preload is equal to $90 \mathrm{~N}$, i.e. for this value of the electrical current the NWR of contact wire increases with the increase of the mean value of contact force. This behaviour can be interpreted considering that the wear phenomenon is mainly the abrasion because the contact temperature is not able to produce the material melting in the contact zone. The tests carried out with electrical current greater than 300 A show wear rate lower than the last one and an increase of the mean value of contact force produces in some cases a decrease of wear rate. This behaviour can be explained considering the combination of two main contributions to the wear, the mechanical contribution and the electrical one. These contributions interact by means of the contact force and the electrical current. The decrease of the mechanical contribution for increasing electrical current can be justified considering the phenomenon called "current lubrication" (already described in $[1,11,12])$, which has the effect of a reduction of abrasive phenomenon typical of the dry contact. The experimental results lead to confirm that the wear of contact wire is caused mainly by three interacting contributions: the first contribution is the mechanical one due to the friction, the second one is the electrical contribution due to the dissipated power caused by the electrical contact resistance and the third one is due to the electrical arcs generated during contact losses. The three contributions are not independent: the mechanical contribution depends on the electrical current ("current lubrication" phenomenon) and the mechanical behaviour of the interaction, 
expressed in terms of contact force variation, influences the electrical contribution (the electrical contact resistance depends on the contact force) and the contribution due to the arc generation (arcs occur when contact losses occur).

In the following section, a numerical model to determine the wear rate of pure copper contact wire is presented: thanks to the experimental results, this wear model has been developed considering the three contributions described above.

\section{The proposed wear model for the pure copper contact wire}

The study reported in this paper is focused to the wear of the contact wire, because typically it has an important impact on the maintenance costs from the infrastructure point of view. Then, the proposed wear model presented in this section was developed starting from a deep analysis of the experimental results related to the contact wire's wear. As reported in section 2, the wear tests on pure copper contact wire interacting with a Kasperovski contact strip pointed out as the wear rate of contact wire depends mutually on both contact force and electrical current. In particular, with higher contact force values $(90 \mathrm{~N})$, the wear rate of contact wire decreases when the electrical current increases, while with lower contact forces the wear behaviour is opposite. If the electrical current value is equal to $300 \mathrm{~A}$, the wear of contact strip increases when the value of contact force increases, while for higher value of electrical current it can decrease. As already discussed, this behaviour can be justified considering that the wear of contact wire is dependent on the combination of two main wear mechanisms, the abrasive wear due to the friction effects and the melting wear. These two wear mechanisms interact by means of the contact force and the electrical current. Moreover, as described in section 2, the "current lubrication" phenomenon is observed. 
The parametric wear model for the contact wire introduced in this section is expressed as a function of the main operating parameters and it presents coefficients that are tuned considering the experimental results using the method of least square. The wear model is composed of three contributions that represent respectively the mechanical contribution to the wear due to friction, the electrical contribution to the wear due to the Joule effect and the last contribution is the one considering the effect of the electrical arcs to the wear. The equation of the considered model is:

$$
N W R=k_{1}\left(\frac{1}{2} \cdot\left(1+\frac{I_{c}}{I_{0}}\right)\right)^{-\alpha} \cdot\left(\frac{F_{m}}{F_{0}}\right)^{\beta} \cdot \frac{F_{m}}{H}+k_{2} \frac{R_{c}\left(F_{m}\right) \cdot I_{c}^{2}}{H \cdot V}(1-u)+k_{3} \cdot u \frac{V_{a} \cdot I_{c}}{V \cdot H_{m} \cdot \rho}
$$

And it corresponds to the assumption of combined influence of electrical current level and contact force ([17]). The equation was developed taking into account that the mechanical contribution is dependent on the level of the electrical current (mechanical contribution decreases when the electrical current increases in order to consider the "current lubrication" phenomenon). The contribution related to the Joule effect increases with the electrical current raised to the second power and it is proportional to the electrical contact resistance, which depends on the contact force. In particular, the expression that provides the electrical contact resistance $R_{c}$ as a function of the contact force $F_{m}$ for the couple "pure copper contact wire Kasperovski contact strip" was obtained by a previous experimental campaign on the test rig described in section 2 and deeply discussed in [14]. For the sake of completeness, in the equation (3) the expression of the electrical contact resistance is reported: 


$$
R_{c}\left(F_{m}\right)=0.013+0.09 \cdot e^{-\frac{F_{m}-14}{11}}
$$

With $F_{m}$ in $\mathrm{N}$ and $R_{m}$ in Ohm. The expressions of the first and second terms in the equation (2) allow to take into account the mutual correlation between the mechanical and electrical contributions.

Finally, the contribution to the wear due to the electrical arcs is proportional to the power generated by the arcs. In particular, as also deeply described in [13], the electrical arc voltage $V_{a}$ typically depends on the distance between the strip and the wire during the contact loss, on the current flowing before the contact loss and on the air flow speed convoyed on the contact zone, i.e. approximately the train speed. In this paper, the contact voltage is considered as a constant value and, also due to the experiences on the previous experimental campaign reported in [13], its value was fixed at $50 \mathrm{~V}$, which represents a good compromise between the simplicity and the reliability of the model. Moreover, the use of method of least square assures the agreement between the laboratory and the model results.

The variables introduced in the equation (2) are described in Table 2. In the same table, the numerical values of these variables, obtained by using the method of least square fitting the experimental results, are reported. The parameters $k_{1}, k_{2}$ and $k_{3}$ represent respectively the coefficients that provide the "weight" to the whole contact wire's wear of the mechanical contribution, of the electrical contribution and of the electrical arcs' contribution.

The Figure 7 shows the comparison between the results obtained by means of the wear model (meshed surface), tuned using the method of least square, and the results obtained by experimental tests (red circles) as a function of the static contact force and of the electrical current. The comparison is made for electrical current values greater than $300 \mathrm{~A}$, because, as 
explained in the section 2.2, the experimental tests with electrical current values in the range $0 \div 200$ A show a wear rate of contact wire quite negligible. The analysis of the Figure 7 shows as the wear rate of contact wire increases mainly for two particular conditions: the first is when the contact force increases and the electrical current value is about $300 \mathrm{~A}$ while the second condition is when the electrical current increases for values of contact force less than about $40 \mathrm{~N}$. The first condition is mainly related to the absence of the current lubrication effect and the main wear mechanism is the abrasion, while the second condition is related to the increase of electrical contribution due to the increase of electrical contact resistance with the decrease of contact force and the main wear mechanism is the melting wear because in this condition the flash temperature in the contact area is very high.

FIGURE 7 TO APPEAR HERE

\section{TABLE 2 TO APPEAR HERE}

FIGURE 8 TO APPEAR HERE

The Figure 8 shows an example of the effect of the three contributions to the wear of contact wire when the electrical current varies, the contact force is equal to $70 \mathrm{~N}$, the sliding speed is fixed to $200 \mathrm{~km} / \mathrm{h}$ and the percentage of contact loss is considered equal to $0.05 \%$. As can be observed, the heuristic wear model has been setup in order to have a decreasing mechanical contribution and an increasing electrical contribution with an increase of the electrical current. The electrical arc's contribution to the whole wear rate of the contact wire increases when the electrical current increases, but it has a very low weight in the whole wear rate value because 
typically, in the normal operation condition, the percentage of contact loss is very low (the maximum value accepted for high speed line by the standard EN50317 "Railway applications - Current collection systems - Technical criteria for the interaction between pantograph and overhead line" is $0.2 \%$ ).

\section{The electromechanical model for the pantograph-catenary interaction}

The main aim of this paper is to provide a method, based on numerical models, to be used in the design stage for the evaluation of potential improvements on the pantograph-catenary system from the contact wire's wear rate point of view. This method has, then, the advantages to assure a very low impact: only if the improvements numerically analysed provide satisfactory results from the contact wire's wear point of view they will be applied and tested in the real system.

Obviously, to obtain reliable results, it is important to reproduce as better as possible the real conditions, included the dynamical interaction conditions that heavily impact on the wear rate of contact wire. As known, the wear rate of the couple "contact strip - contact wire" depends on the main operation parameters (train speed, electrical current, contact force), on the materials of the contacting bodies and, as already said, on the dynamical interaction between them. In particular, this last aspect influences the instantaneous values of contact force, which determines the instantaneous value of the electrical contact resistance and the percentage of contact loss, and of the electrical current flowing in the contact zone. It is clear, then, that the analysis of the dynamical conditions during the interaction between the pantograph and the catenary is fundamental for the evaluation of the contact wire's wear.

In order to take into account all the aspects discussed above, the proposed method uses in combination the wear model presented in section 3 and a numerical model able to reproduce 
the electromechanical phenomena that occur during the dynamical interaction between the pantograph and the catenary.

The numerical model for the study of the dynamical pantograph-catenary interaction is a mathematical model able to reproduce the dynamical phenomena in the range up to $100 \mathrm{~Hz}$, developed by the researchers of the Department of Mechanical Engineering of Politecnico di Milano. As deeply described in [18], the model was validated by means of experimental results obtained by in-line tests. The overhead equipment (OHE) is modelled by means of tensioned beam elements using the finite element representation and the droppers are modelled as non-linear elements in order to consider the effect of their slackening in compression. The pantograph is modelled by using a lumped parameter model for the frame combined with a modal representation of the collectors (their rigid and deformable modes are considered using the superposition modal approach). Finally, the contact model is based on the penalty method, tuned to provide the mono-lateral contact between contact strip and contact wire correctly ([19]). The simulation of pantograph-catenary dynamic interaction is performed in the time domain, with the possibility to include the contact wire irregularity.

FIGURE 9 TO APPEAR HERE

In order to consider the dynamics of the electrical current flowing between the contact wire and the contact strip, a very simple electrical model has been introduced. The electrical scheme is reported in Figure 9 and a pantograph with two contact strips is considered. The electrical model considers the connection in parallel of the two contact strips. Each contact strip is characterised from the electrical point of view by the related electrical contact 
resistance $R_{c i}\left(F_{m i}\right)$, which depends on the instantaneous contact force $F_{m i}$ between the $i^{\text {th }}$ contact strip and the contact wire by the equation (3), and by an inductance $\mathrm{L}_{\mathrm{c}}$, considered equal for both strip. This last element has been introduced to take into account the inductive behaviour of the electrical arc: in this way, during a contact loss between the contact strip and the contact wire, the passage of the electrical current is not instantaneously broken off, but it has dynamical variations. This very simple electrical model allows to obtain a more realistic behaviour of the simulated pantograph-catenary interaction. The electrical equations are the following:

$\left\{\begin{array}{l}i_{1}+i_{2}=I=\text { const } \\ L_{c} \frac{d i_{1}}{d t}-L_{c} \frac{d i_{2}}{d t}+R_{c 1}\left(F_{m 1}\right) i_{1}-R_{c 2}\left(F_{m 2}\right) i_{2}=0\end{array}\right.$

and they are integrated in the time domain in order to calculate the electrical current flowing in each strip ( $i_{1}$ and $i_{2}$ ). The first equation in (4) means that the traction system of the train can be represented as a generator of constant current. As discussed in [13], the traction controller design is typically chosen in order to correlate the traction torque to the voltage of the input filter of the train's electrical drive. Considering that the electrical power, given by the product between voltage and current, is converted in the mechanical power, given by the product between torque and angular speed, if a constant speed is considered, it is possible to consider the collected current as a constant value (for further details, see [13]).

FIGURE 10 TO APPEAR HERE 
The scheme represented in the Figure 10 explains how the method works:

a. the input data are the electromechanical model data, i.e. the mechanical data of the couple "pantograph-catenary" to be simulated, the contact wire irregularity and the train speed;

b. the outputs of the electromechanical model, which represent the inputs for the proposed heuristic wear model, are the contact force between the contact wire and each contact strip of the pantograph, the corresponding electrical contact resistance (calculated by means of the equation (3)), the percentage of contact loss and the electrical current flowing in each contact strip (obtained by the time integration of equation (4));

c. once known all the parameters needed by the wear model, characterised by the equation (2), it is possible to obtain the final output, i.e. the wear rate of the contact wire, which allows to obtain the contact wire's wear in terms of worn area and of thickness of contact wire. The latter variable represents the new irregularity of the wire and it can be used to start a new cycle of the presented procedure in order to assess the evolution of contact wire's wear for a fixed period of operation.

\section{An application of the presented method: the effect of wire irregularity on the evolution of contact wire's wear}

In the present section, an application of the method for the estimation of the wear evolution of contact wire, described in the previous sections, is reported. The pantograph-catenary couple analysed has been the one typically used in the d.c. Italian railway operation, i.e. the $3 \mathrm{kV}$ ATR95 pantograph, with two Kasperovski contact strips, and the C440 catenary. The simulated catenary is composed of two contact wires with a section of $100 \mathrm{~mm}^{2}$ and 
mechanical tension of $10 \mathrm{kN}$ and of two messenger wires with a section of $120 \mathrm{~mm}^{2}$ and a mechanical tension of $11.25 \mathrm{kN}$ (the total section of the catenary is $440 \mathrm{~mm}^{2}$ ). A $60 \mathrm{~m}$ span length has been considered. In Figure 11, a scheme of the simulated catenary for a single span is reported. In the simulation, the deformability of contact strip has been considered and the maximum length of the tensioned beam element of contact wire has been $0.25 \mathrm{~m}$ in order to reproduce the dynamical interaction between pantograph and catenary at high frequency. In particular, in the analysis the maximum frequency contribution for contact force results has been $100 \mathrm{~Hz}$. During simulation, $600 \mathrm{~m}$ of catenary, i.e. 10 spans, and a constant value of the total collected electrical current, equal to $2000 \mathrm{~A}$, have been considered.

\section{FIGURE 11 TO APPEAR HERE}

Since the aim of the analysis is to assess the evolution of contact wire's wear considering the electromechanical dynamics of interaction between pantograph and catenary, in order to consider the variability of the conditions of real operation, the simulations have been performed considering the nominal train speed, chosen for this analysis equal to $200 \mathrm{~km} / \mathrm{h}$, and a variation of $\pm 3 \mathrm{~km} / \mathrm{h}$ from the nominal value. Moreover, the six spans in the middle of the simulated track (the first two spans and the last two spans have not been kept into account to avoid boundary effects) for each simulated vehicle speed have been used to create a statistical sample (then composed of 18 spans) in order to better reproduce the variability of real conditions.

The application of the method presented in this work concerns the effect of the wire irregularity, i.e. defects on the laying in terms of variation of height of catenary along the line before operation, on the evolution of contact wire's wear. Three different conditions have 
been analysed: i) no wire irregularity, ii) low level of wire irregularity and iii) high level of wire irregularity. The high level of wire irregularity comes from a real measurement of the height of catenary in bad conditions while the low level of wire irregularity is obtained as the $25 \%$ of the high level wire irregularity.

As shown in Figure 10, to assess the evolution of contact wire's wear, the method is applied repeating the procedure and modifying each time the new wire irregularity input, which is obtained by multiplying the thickness of contact wire after the occurred wear and the number of pantograph passages. This last parameter is calculated as the multiplication between the pantograph passages a day and the time interval in which it is possible to hypothesize a constant evolution of contact wire. In order to analyse the effect of the time interval value on the contact wire's wear evolution, two time interval values have been considered just for the simulation without contact wire irregularity: 2 months, corresponding to 6000 pantograph passages, and 6 months, corresponding to 18000 pantograph passages. After showing some examples of contact force results for the two contact strips of the pantograph in the six considered span (track space between $120 \mathrm{~m}$ and $480 \mathrm{~m}$ ) and the corresponding electrical contact resistance and the electrical current flowing in each contact strip (Figure 12), the effect of the different time interval value considered to assess the evolution of contact wire's wear in correspondence of two particular sections, i.e. under suspension and at midspan, is reported (Figure 13).

FIGURE 12 TO APPEAR HERE

FIGURE 13 TO APPEAR HERE 
The analysis of Figure 13 leads to state that the hypothesis of constant wear rate evolution for the time interval of 6 months produces in 36 months a higher wear value of about $20 \%$ for section under suspension and $6 \%$ for section at midspan with respect to the time interval of 2 months. For this reason, in order to avoid the introduction of inaccuracies to the final results due to a wrong hypothesis of constant wear rate evolution, for the simulated conditions with wire irregularity a time interval of 2 months has been used.

\section{FIGURE 14 TO APPEAR HERE}

Results of effect of contact wire irregularity on the contact wire's wear evolution are reported in Figure 14. Also in this case, the contact wire's worn areas for section under suspension and for section at mid span are reported. The first comment to the results concerns the different values of contact wire's worn area obtained for the section under suspension and for the section at midspan: for each wire irregularity considered in the present analysis, the wear of contact wire is always higher for section under suspension. This is explained by considering that along the span the stiffness of contact wire changes, decreasing not uniformly due to the presence of droppers from the suspension to the midspan. Under suspension the high value of wire's stiffness produces a variation on the contact force, that can be either a contact loss or a high value of contact force, causing a faster evolution of wire's wear. This behaviour is proved also by the experience acquired by the real operation. The wear results in the presented analysis show higher values of worn area for the section under suspension of about $20 \%$ and $30 \%$ with respect to the section at midspan. 
From the analysis of Figure 14 the effect of the wire irregularity on the wire's worn area value for both section under suspension and at mid span is very evident: the difference between the case without wire irregularity and with low wire irregularity is less than $10 \%$ in the worn area value, while the case with high level of wire irregularity produces an increase of wire's worn area value of about $35 \% \div 40 \%$ with respect to the case with low level of wire irregularity for both considered sections. This result is explained with the high variation of contact force produced by the high level of contact wire's irregularity that causes an important level of wire's wear with respect to an ideal condition of the catenary's contact wire.

\section{FIGURE 15 TO APPEAR HERE}

Analysing the corresponding evolution of contact wire's thickness (Figure 15) the same comments can be done, even though the variation of this parameter is less important than the worn area (the maximum variation of wire's thickness is obtained for the section under suspension where with high level of wire irregularity a decrease of $10 \%$ of wire's thickness is estimated with respect to the case without wire irregularity).

\section{Conclusions}

In this work experimental investigation on the contact wire's wear for the couple "Kasperovski contact strip - pure copper contact wire" in d.c. current operation has been presented. A heuristic wear model, whose parameters are tuned by means of the laboratory test results, considering mechanical, electrical and arcing contributions interacting each other, has been proposed. This model, providing a relationship between the wear rate of the contact wire and the main parameters of the current collections (sliding speed, contact force, electrical current), can be used in combination with a numerical model able to simulate the dynamics of 
the electromechanical interaction between pantograph and catenary. The combined use of these numerical models represents a procedure able to evaluate the evolution of the wear on the contact wire. During the analysis, the variability of the train speed and the variability of the contact conditions have been considered in order to obtained a statistical sample for the analysis of wear along the span. As an example, in this work the procedure has been applied to evaluate the effect of the wire irregularity, i.e. the effect of defects on the laying in terms of variation of height of catenary along the line before operation, on the contact wire's wear evolution.

The presented procedure can be used in the design stage for the evaluation of potential improvements on the pantograph-catenary system from the contact wire's wear rate point of view. The main advantages of the presented procedure is to be a very low impact method: only if the improvements numerically analysed provide satisfactory results from the contact wire's wear point of view they will be apply and tested in the real system.

\section{References}

[1] Klapas, D., Benson, F. A., Hackam, R., Evison, P. R. Wear in simulated railway overhead current collection systems, Wear, 126, 1988, p. 167-190.

[2] Becker, K., Rukwied, A., Zweig, W., Resch, U. Simulation of the wear behaviour of high-speed overhead current collection systems, Computational Methods and Testing for Engineering Integrity, 1996, p. 281-290.

[3] Kubo, S., Kato, K. Effect of arc discharge on wear rate of Cu-impregnated carbon strip in unlubricated sliding against $\mathrm{Cu}$ trolley under electric current, Wear, 216, 1998, p. $172-178$. 
[4] Kubo, S., Kato, K. Effect of arc discharge on the wear rate and wear mode transition of a copper-impregnated metallized carbon contact strip sliding against a copper disk, Tribology International, 32, 1999, p. 367-378.

[5] Nagasawa, H., Kato, K. Wear mechanism of copper alloy wire sliding against ironbase strip under electric current, Wear, 216, 1998, p. 179-183.

[6] Zhao, H., Barber, G. C., Liu, J. Friction and wear in high speed sliding with and without electrical current, Wear, 249, 2001, p. 409-414.

[7] He, D. H., Manory, R., Grady, N. Wear of railway contact wires against current collector materials, Wear, 215, 1998, p. 146-155.

[8] He, D. H., Manory, R., Sinkis, H. A sliding wear tester for overhead wires and current collectors in light rail systems, Wear, 239, 2000, p. 10-20.

[9] Usuda, T., Ikeda, M., Yamashita, Y. Prediction of contact wire wear in high-speed railways, $9^{\text {th }}$ World Congress on Railway Research, Lille - France, May 21-26, 2011

[10] Lim, S. C., Ashby, M. F. Wear-mechanism maps, Acta Metallurgica, Vol. 35, pp. 1-24.

[11] Bucca, G., Collina, A. A procedure for the wear prediction of collector strip and contact wire in pantograph-catenary system, Wear 266, 2009, p. 46-59.

[12] Bruni, S., Bucca, G., Collina, A., Facchinetti, A., Melzi, S. Pantographcatenary dynamic interaction in the medium-high frequency range, Vehicle System Dynamics Supplement, Vol. 41, 2004, p. 697-706.

[13] Bucca, G., Collina, A., Manigrasso, R., Mapelli, F., Tarsitano, D. Analysis of electrical interferences related to the current collection quality in pantograph-catenary 
interaction, Proceedings of the Institution of Mechanical Engineers, Part F: Journal of Rail and Rapid Transit 225 (5), 2011, p. 483-499.

[14] Kubota, Y., Nagasaka, S., Miyauchi, T., Yamashita, C., Kakishima, H., Sliding wear behavior of copper alloy impregnated $\mathrm{C} / \mathrm{C}$ composites under an electrical current, Wear 302 (1-2), 2013, p. 1492-1498.

[15] Ding, T., Chen, G.X., Wang, X., Zhu, M.H., Zhang, W.H., Zhou, W.X., Friction and wear behavior of pure carbon strip sliding against copper contact wire under AC passage at high speeds, Tribology International 44 (4), 2011, p. 437-444.

[16] Chen, G.X., Yang, H.J., Zhang, W.H., Wang, X., Zhang, S.D., Zhou, Z.R., Experimental study on arc ablation occurring in a contact strip rubbing against a contact wire with electrical current, Tribology International 61, 2013, p. 88-94.

[17] Borgwartd, H. Verschlei $\square$ Verhalten des Fahrdrat der Oberlaitung. Elektrische Bahnen, 1989.

[18] Collina, A., Bruni, S. Numerical simulation of pantograph-overhead equipment interaction, Vehicle System Dynamics, 2002, Vol.38 (n.4),pp.261-291.

[19] Bathe, K. J. Finite Element Procedure, Prentice Hall, 1996. 


\section{List of Figures}

Figure $1 \quad$ Kasperovski contact strip: a) Overview; b) width of strip and thickness of copper part.

Figure 2 Scheme of the test rig.

Figure $3 \quad$ Instrumented contact strip specimen.

Figure 4 Selected sections along the wire for the measurement of thickness variation of the contact wire.

Figure 5 Experimental results obtained during laboratory tests: NWR of Kasperovski contact strip vs electrical current.

Figure $6 \quad$ Experimental results obtained during laboratory tests: NWR of pure copper contact wire vs electrical current.

Figure $7 \quad$ a) Comparison between laboratory results of contact wire's wear rate and results obtained by the tuned wear model as a function of current for the two tested static preload $\left(F_{m}=60 N\right.$ and $\left.F_{m}=90 N\right)$; b) NWR of contact wire obtained by the wear model as a function of static contact force and of electrical current.

Figure $8 \quad$ NWR of contact wire provided by the wear model with $F_{m}=70 \mathrm{~N}$, $\mathrm{u}(\%)=0.05, \mathrm{~V}=200 \mathrm{~km} / \mathrm{h}$ : trend of the three contribution to the wear (mechanical contribution, electrical contribution and electrical arcs' contribution) and of the whole wear of contact wire as a function of the electrical current.

Figure 9 Scheme used for the simple electrical model of the interaction between pantograph and catenary.

Figure 10 Scheme of the procedure to obtain the wear rate of contact wire using the proposed method.

Figure 11 Scheme of a span (60 m length) of the C440 simulated catenary. 
Figure 12 Example of contact force results for the two contact strips (top) and of the corresponding electrical contact resistance (middle) and collected electrical current (down).

Figure 13 Comparison between the evolution of contact wire's worn area under suspension (a) and at midspan (b) using two different time interval steps: 2 months (red curve) and 6 months (blue curve).

Figure 14 Comparison between the evolution of contact wire's worn area under suspension (a) and at midspan (b) for different initial condition of level of contact wire irregularity.

Figure 15 Comparison between the evolution of contact wire's thickness under suspension (a) and at midspan (b) for different initial condition of level of contact wire irregularity. 


\section{List of Tables}

Table 1 The sequence of the wear tests.

Table 2 Variables and parameters present in the wear model of contact wire 


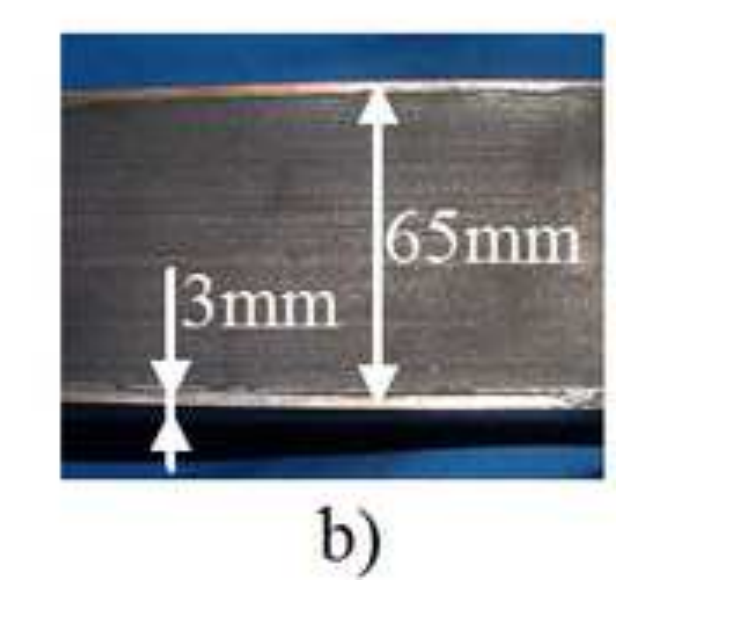

b)
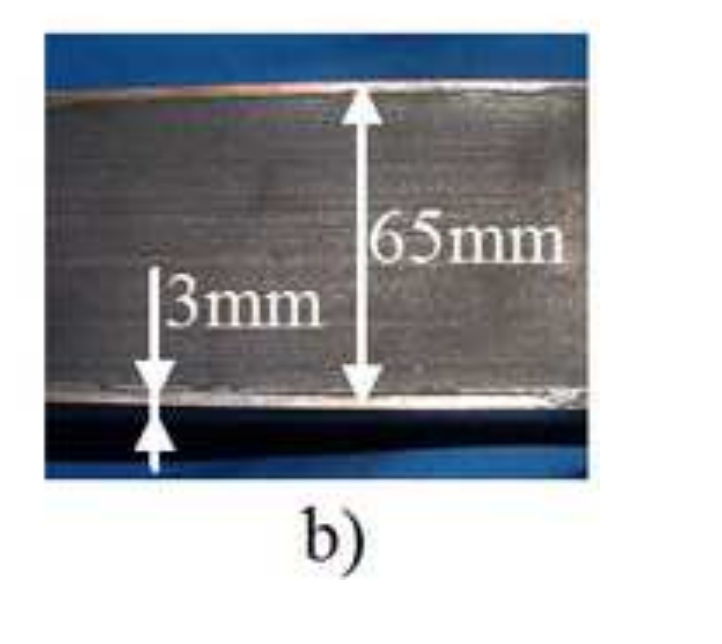

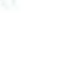

Carbon part

a)

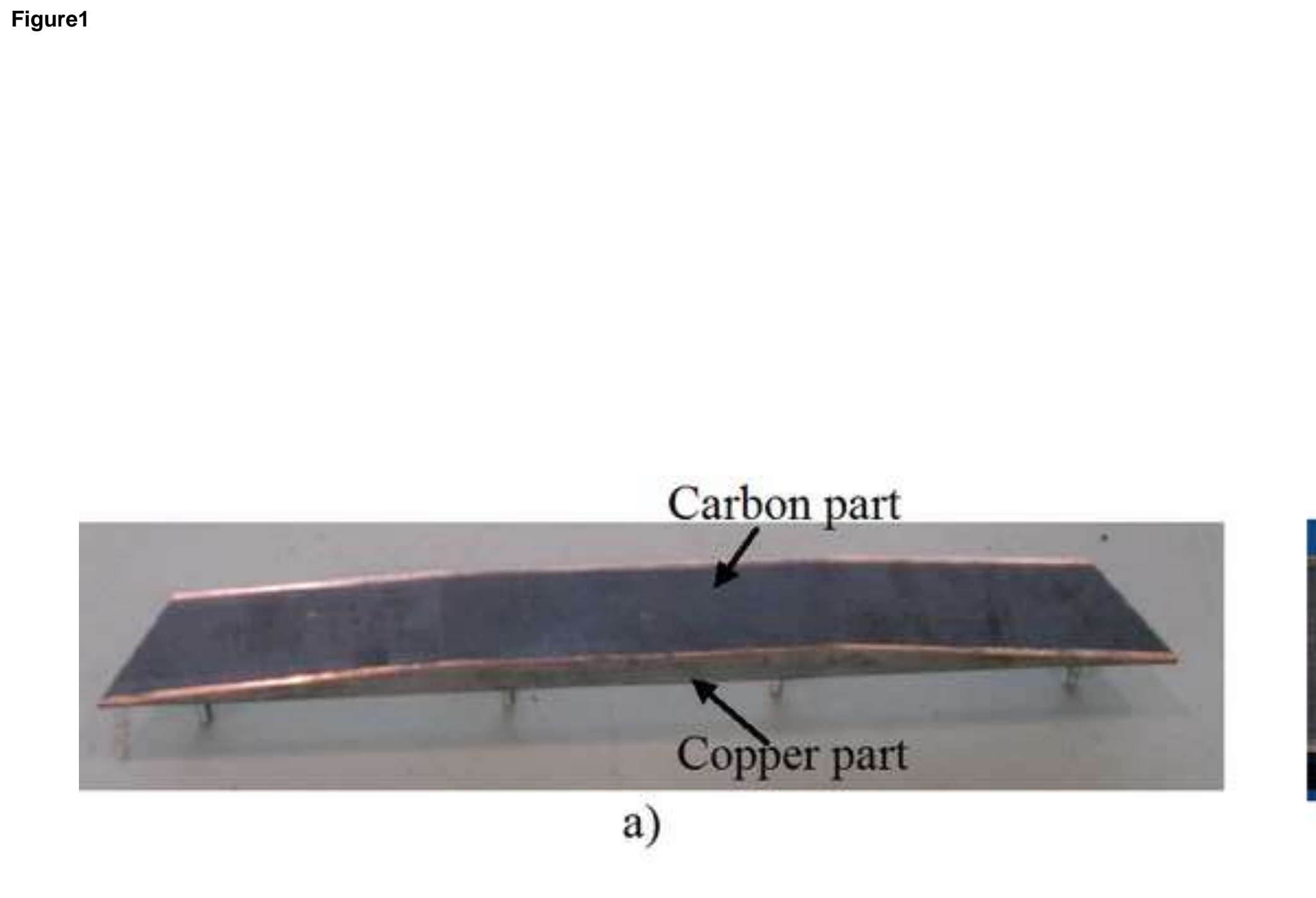

\section{Copper part}

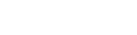

政 
FRONT VIEW

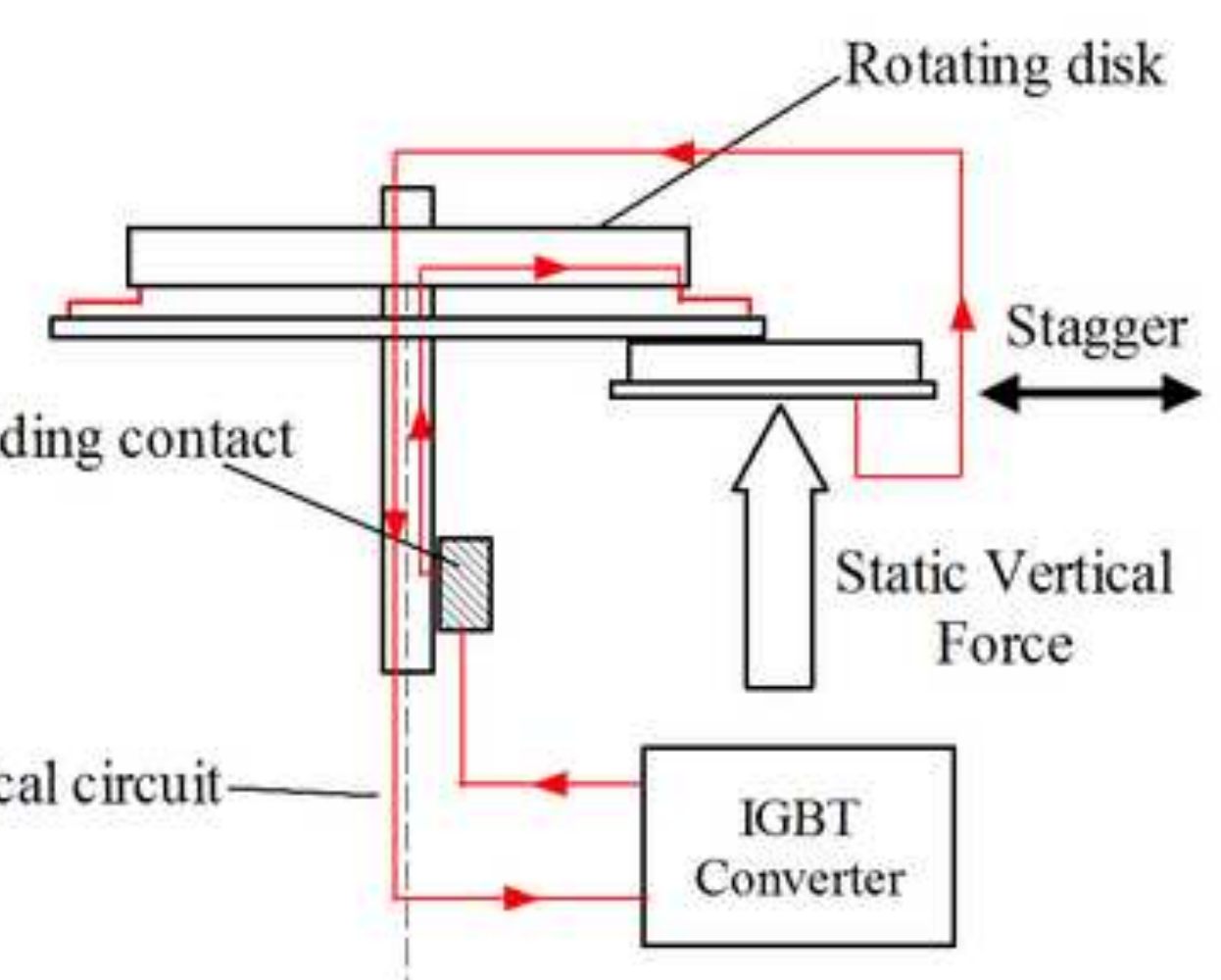

Electrical circuit

TOP VIEW

\section{Contact wire}

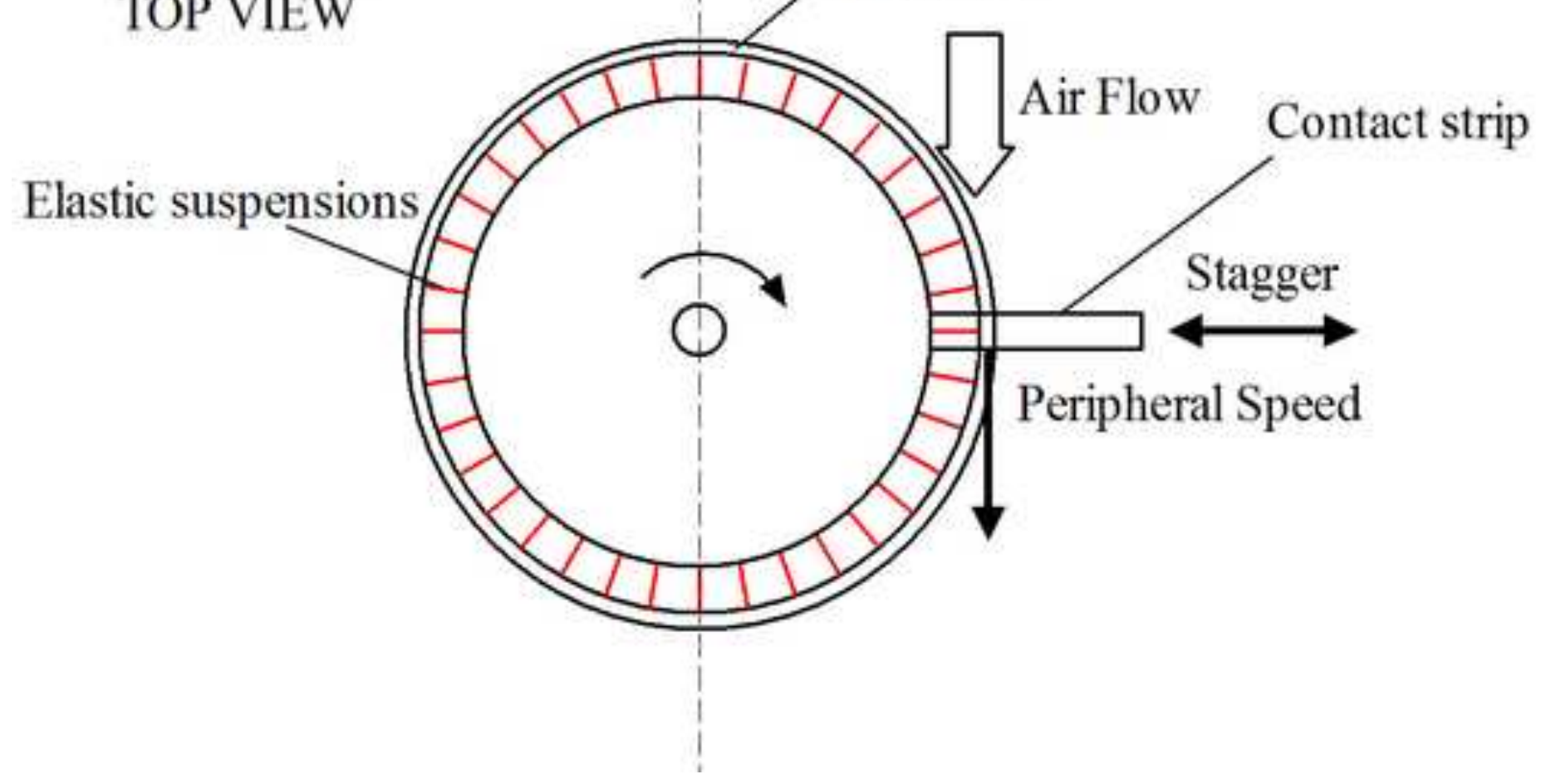




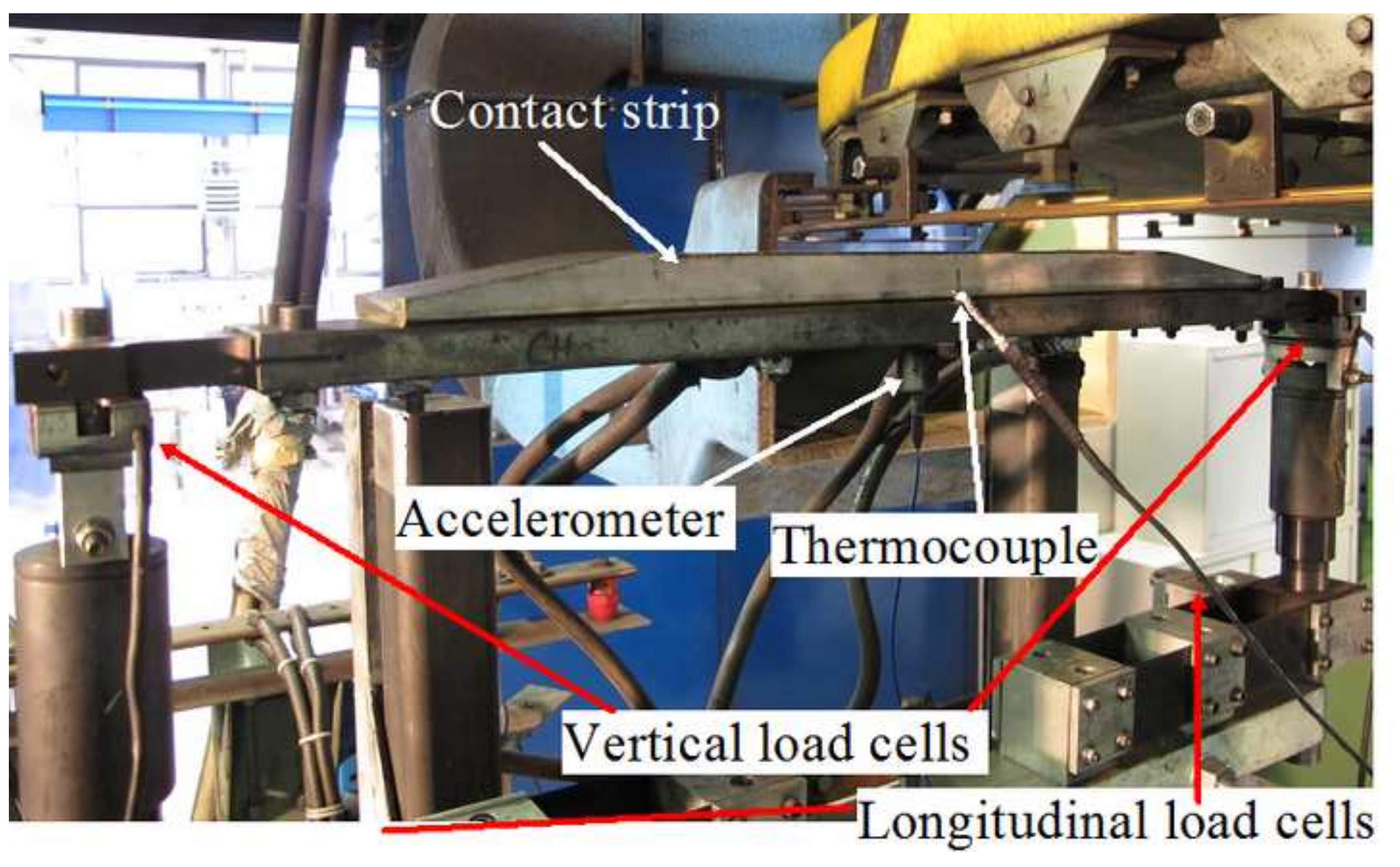

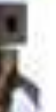


Velocity

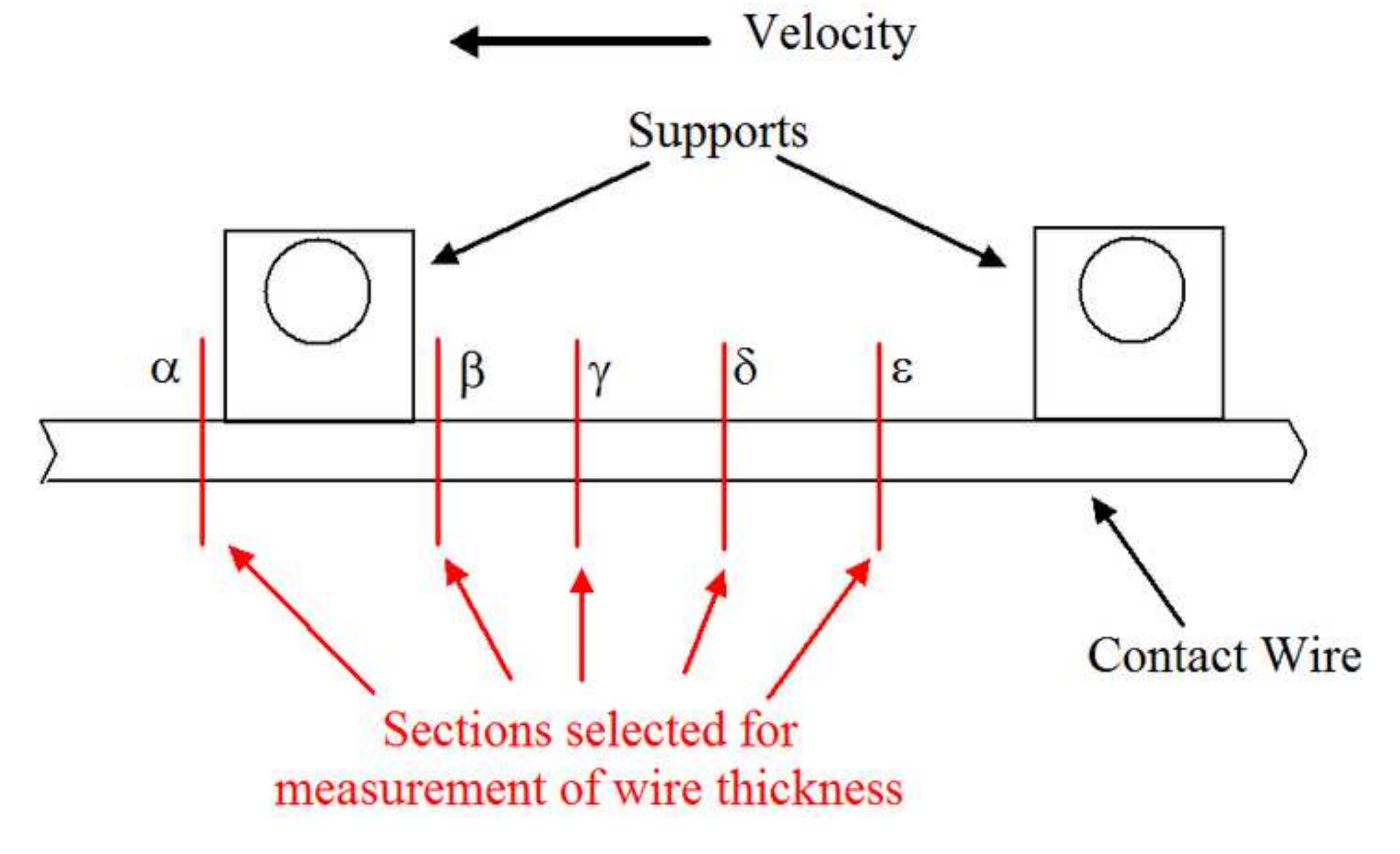

Sections selected for
surement of wire thickness

Sections selected for
measurement of wire thickness
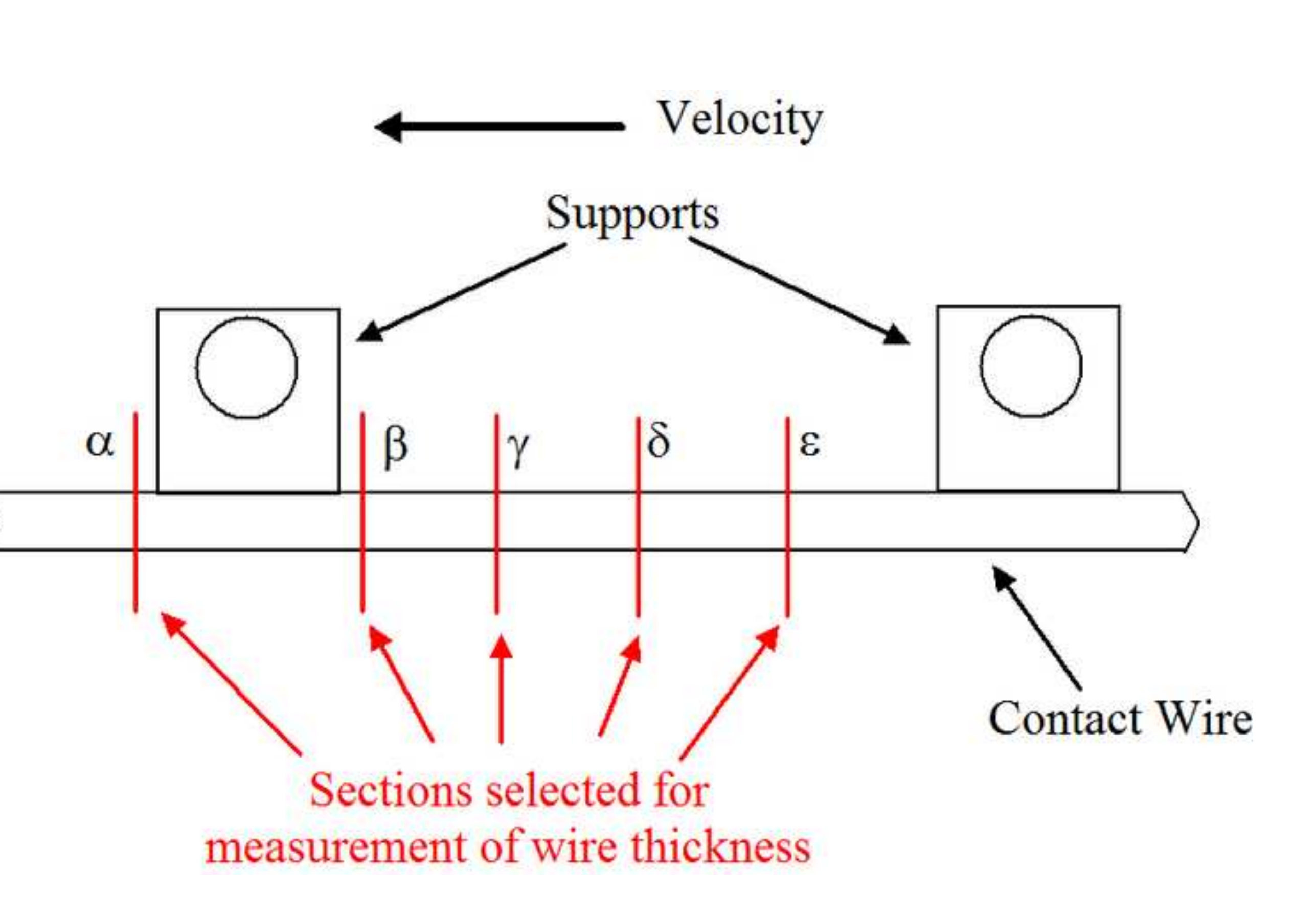

\section{measurement of wire thickness}
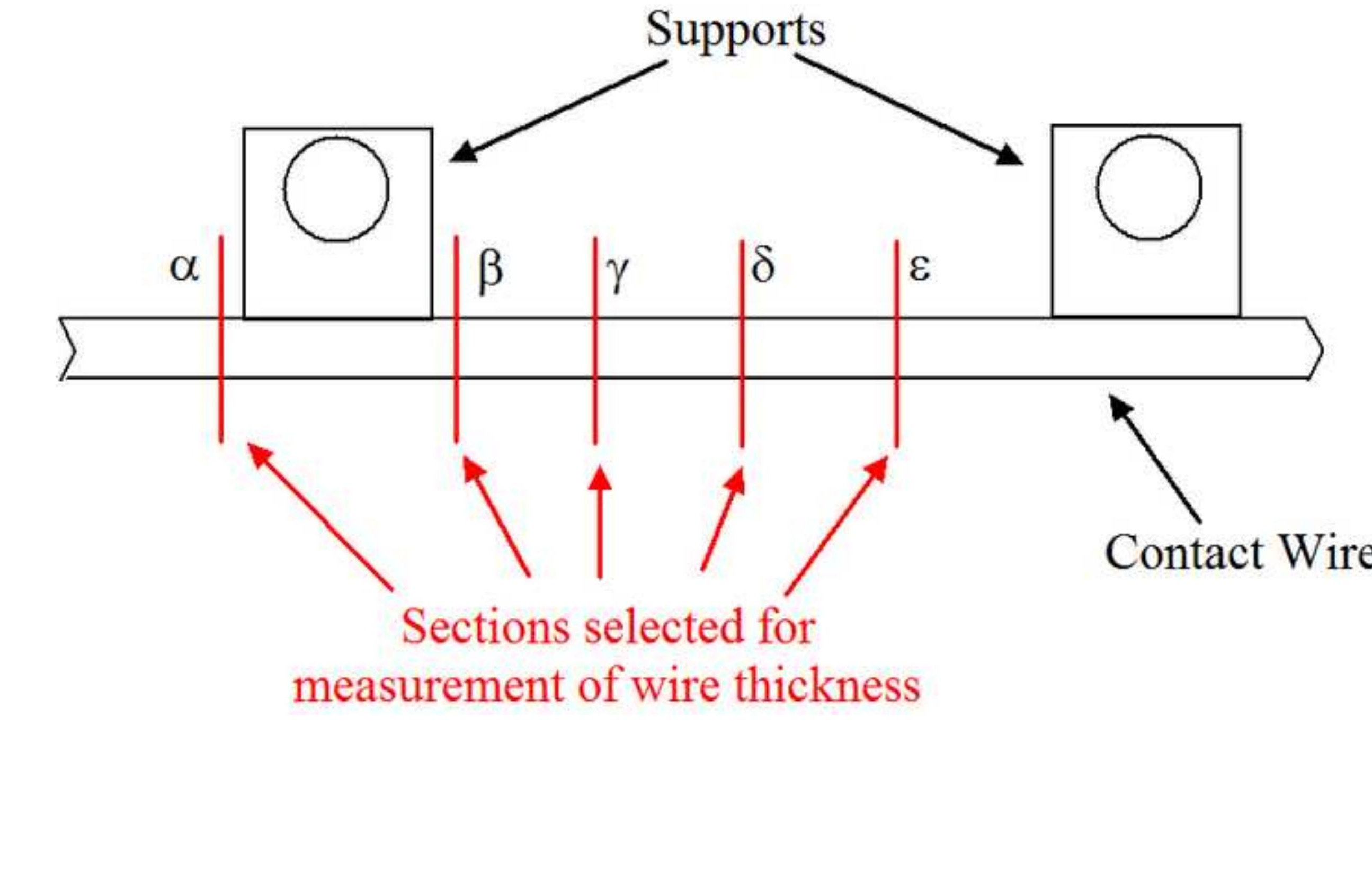


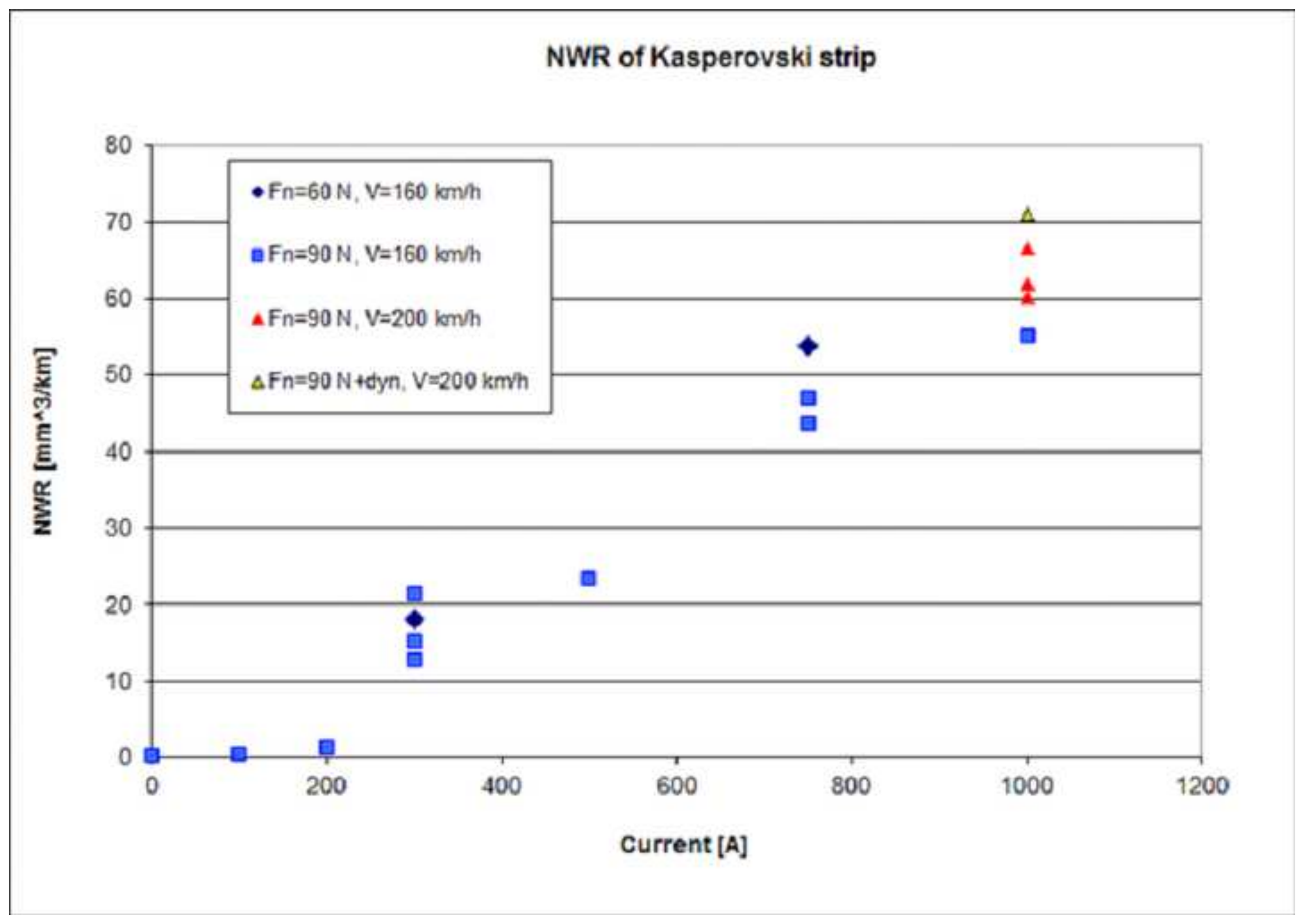

\section{NWR of Kasperovski strip}




\section{NWR of contact wire}

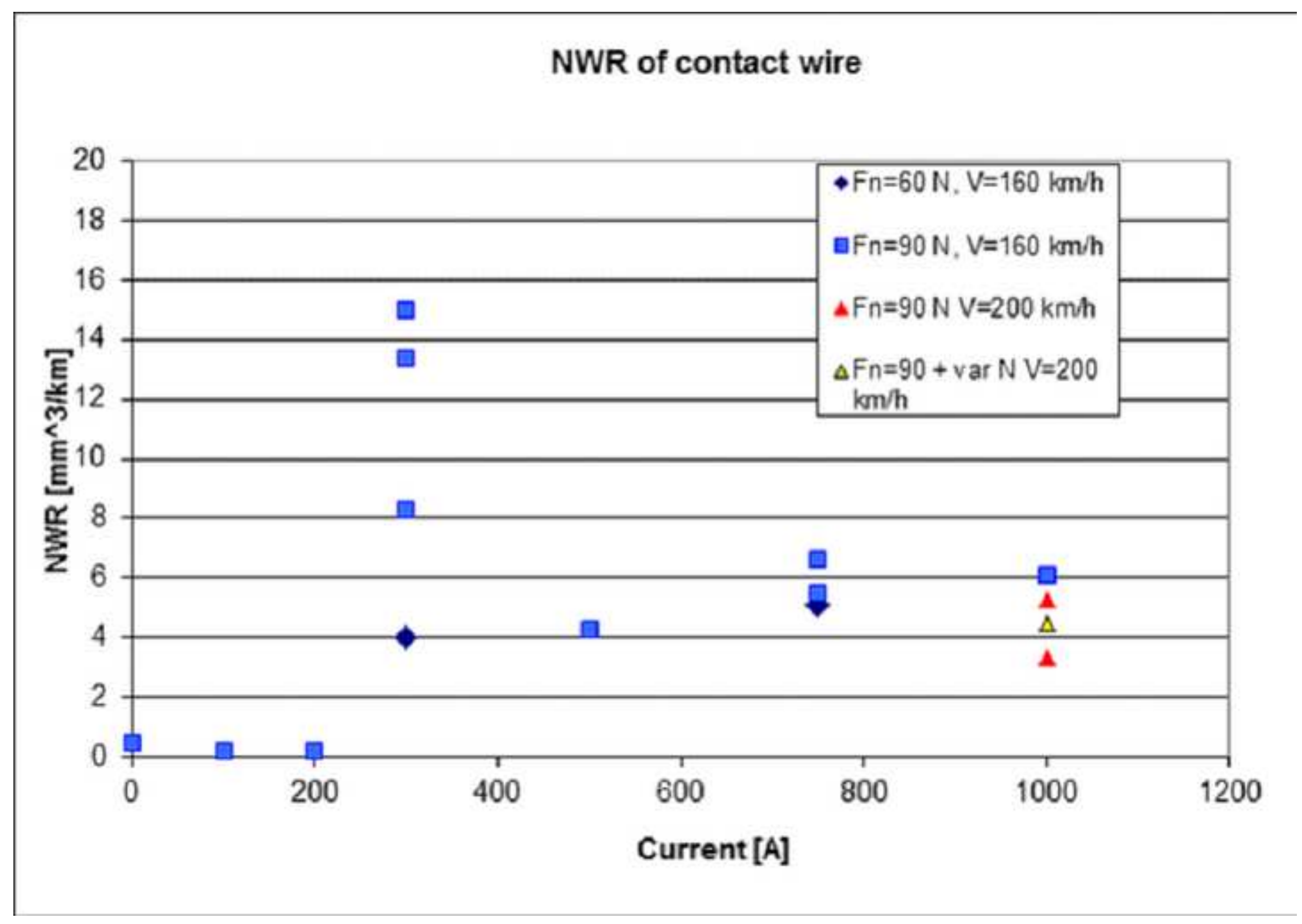


Figure7a
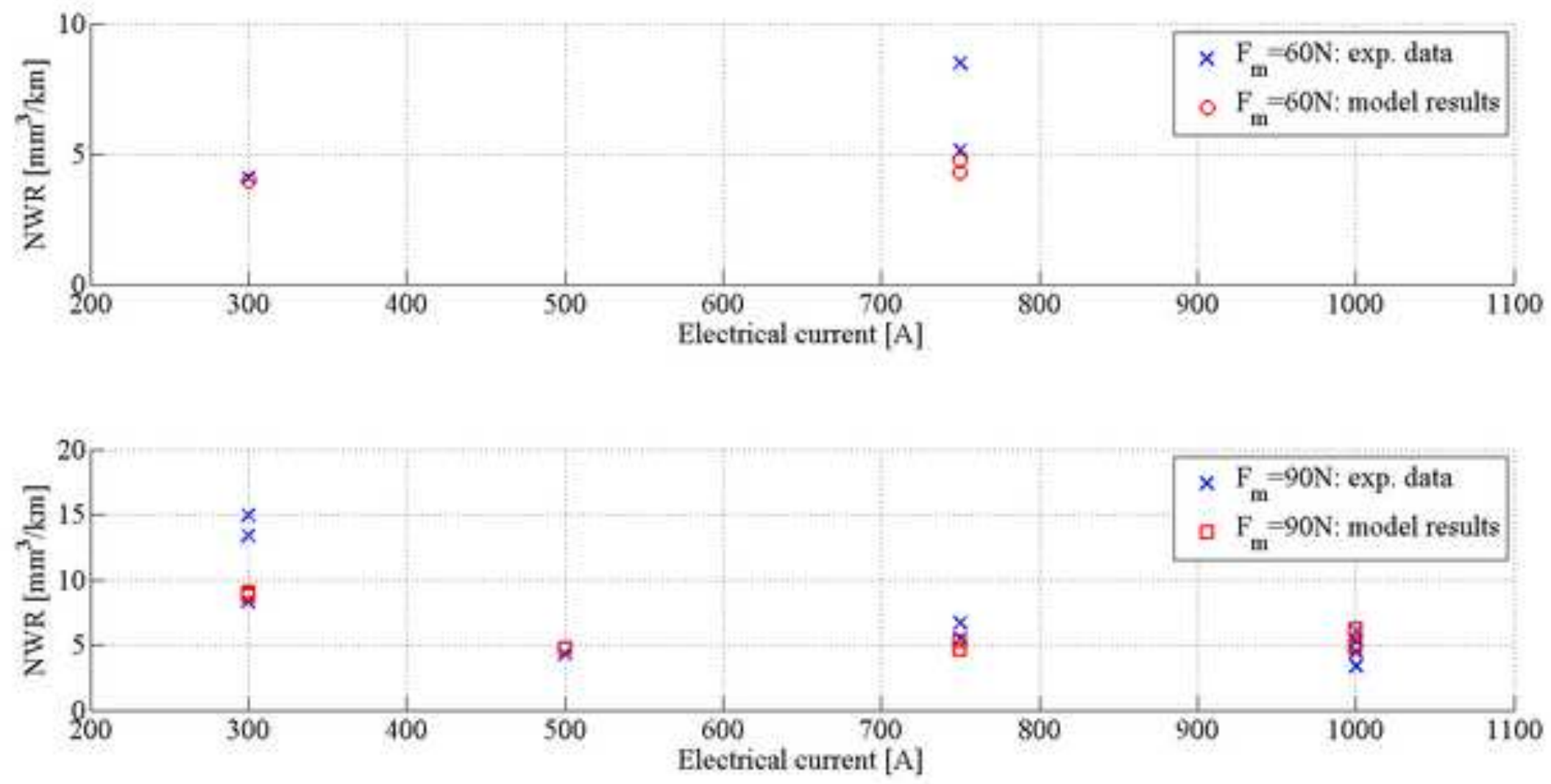
Figure7b

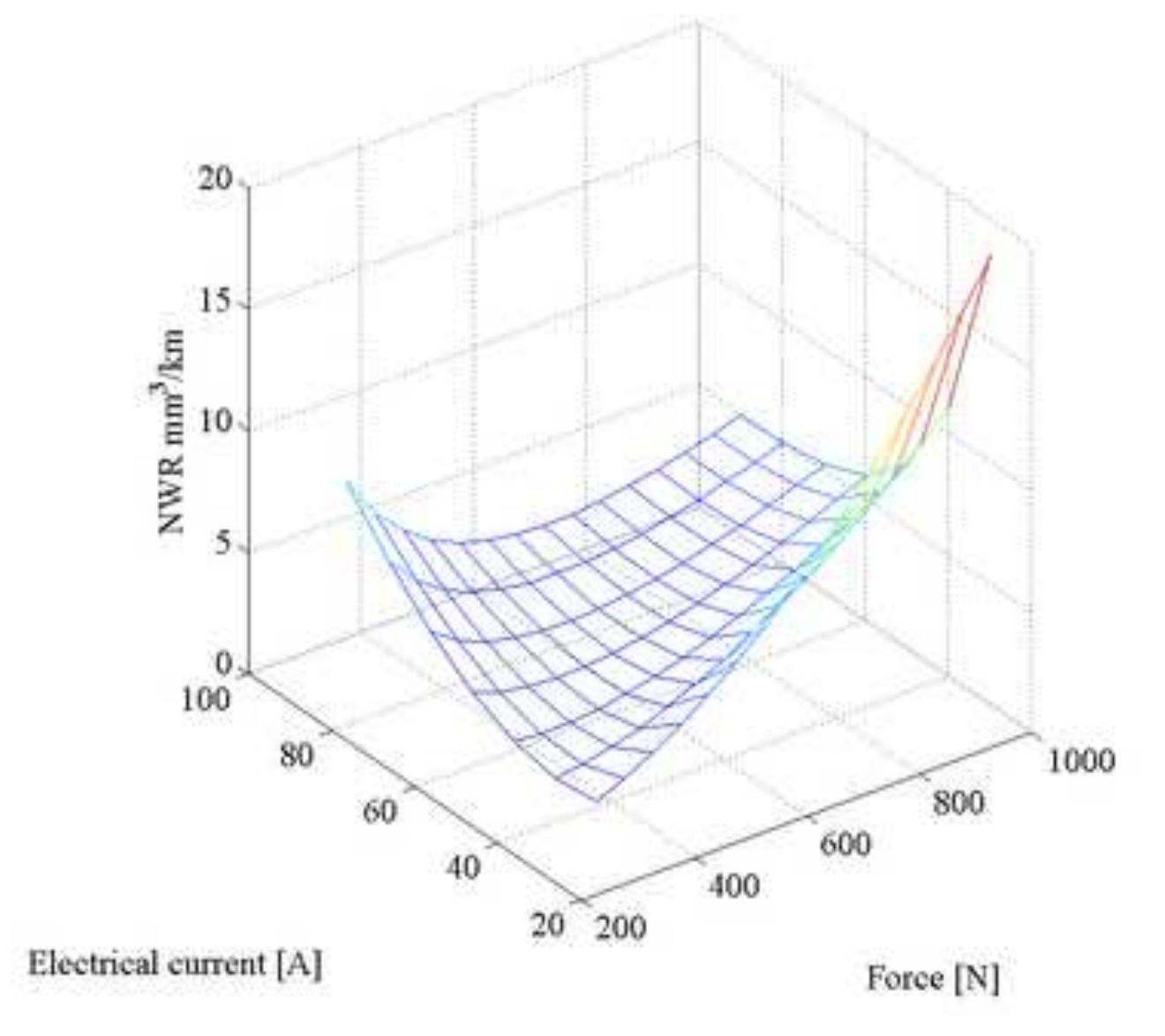

Electrical current [A]

Force [N]

-

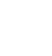




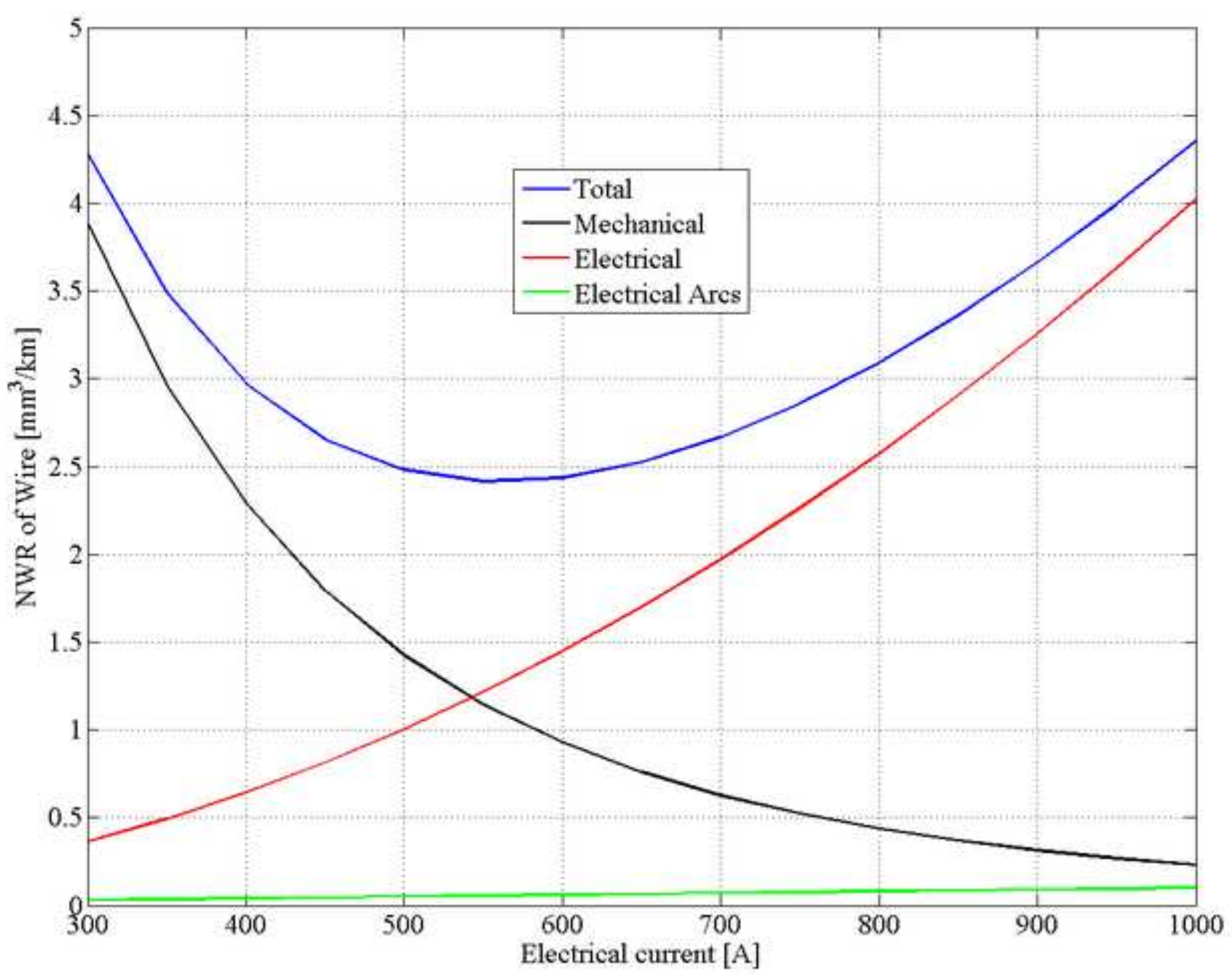




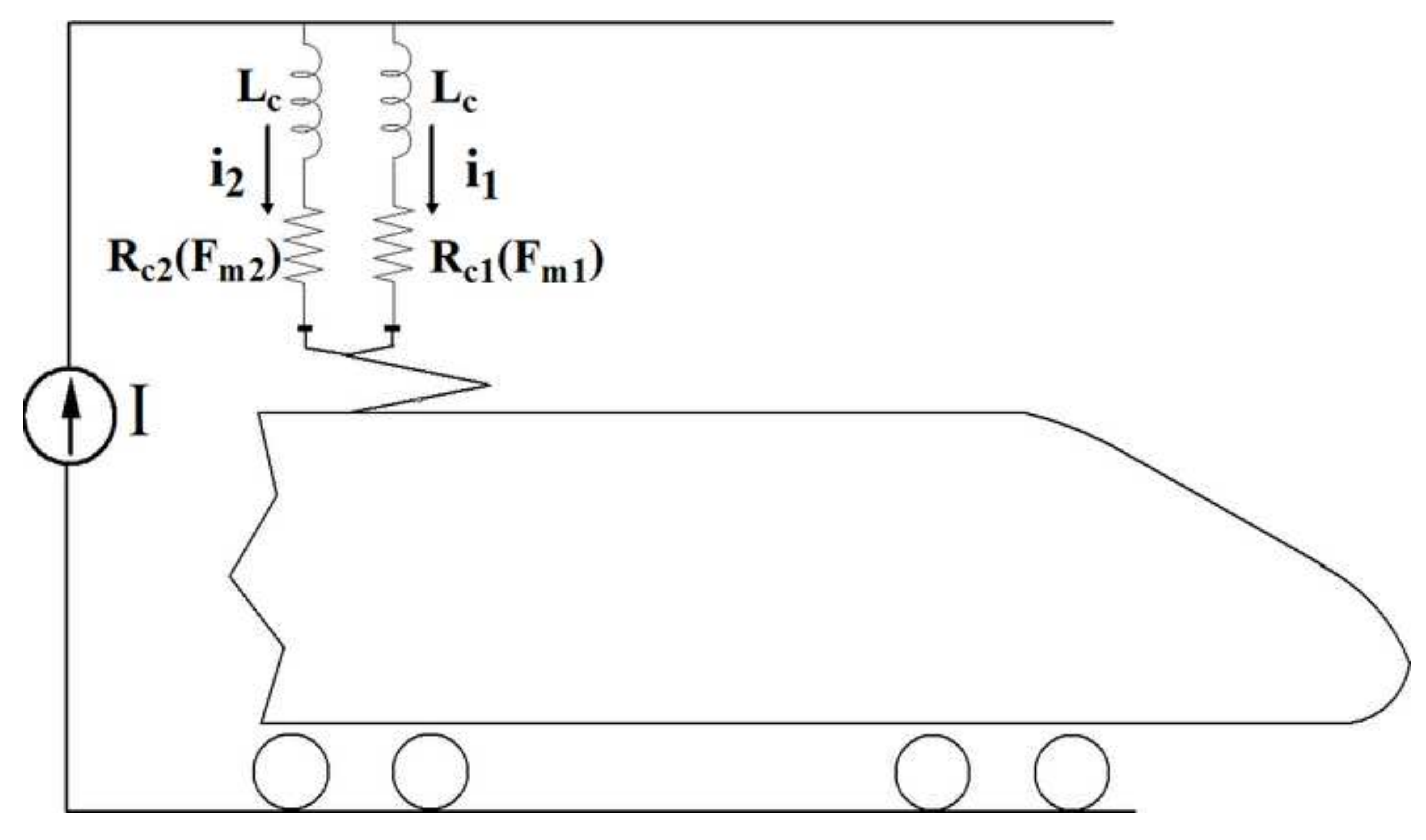


Electromechanical Output and

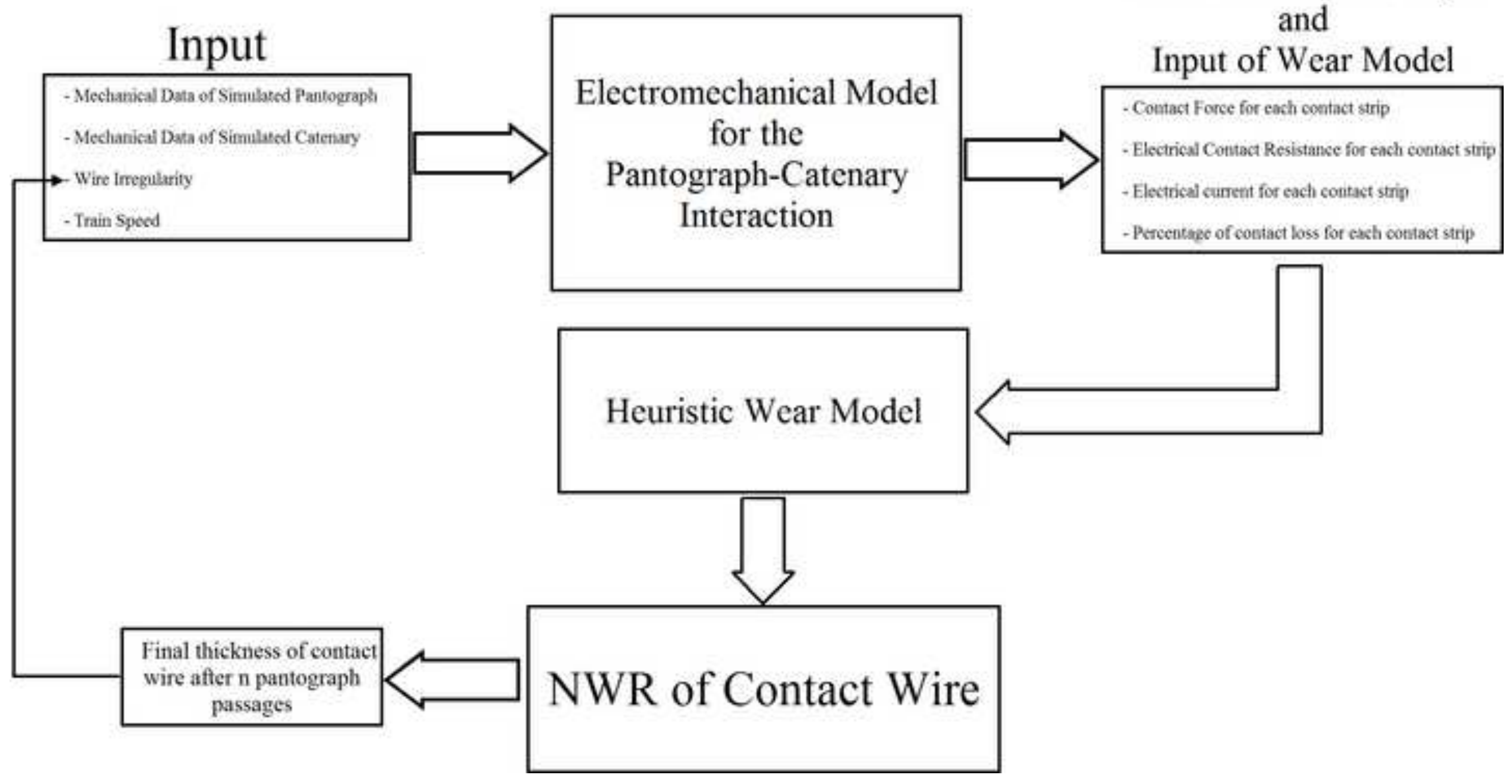


Figure11

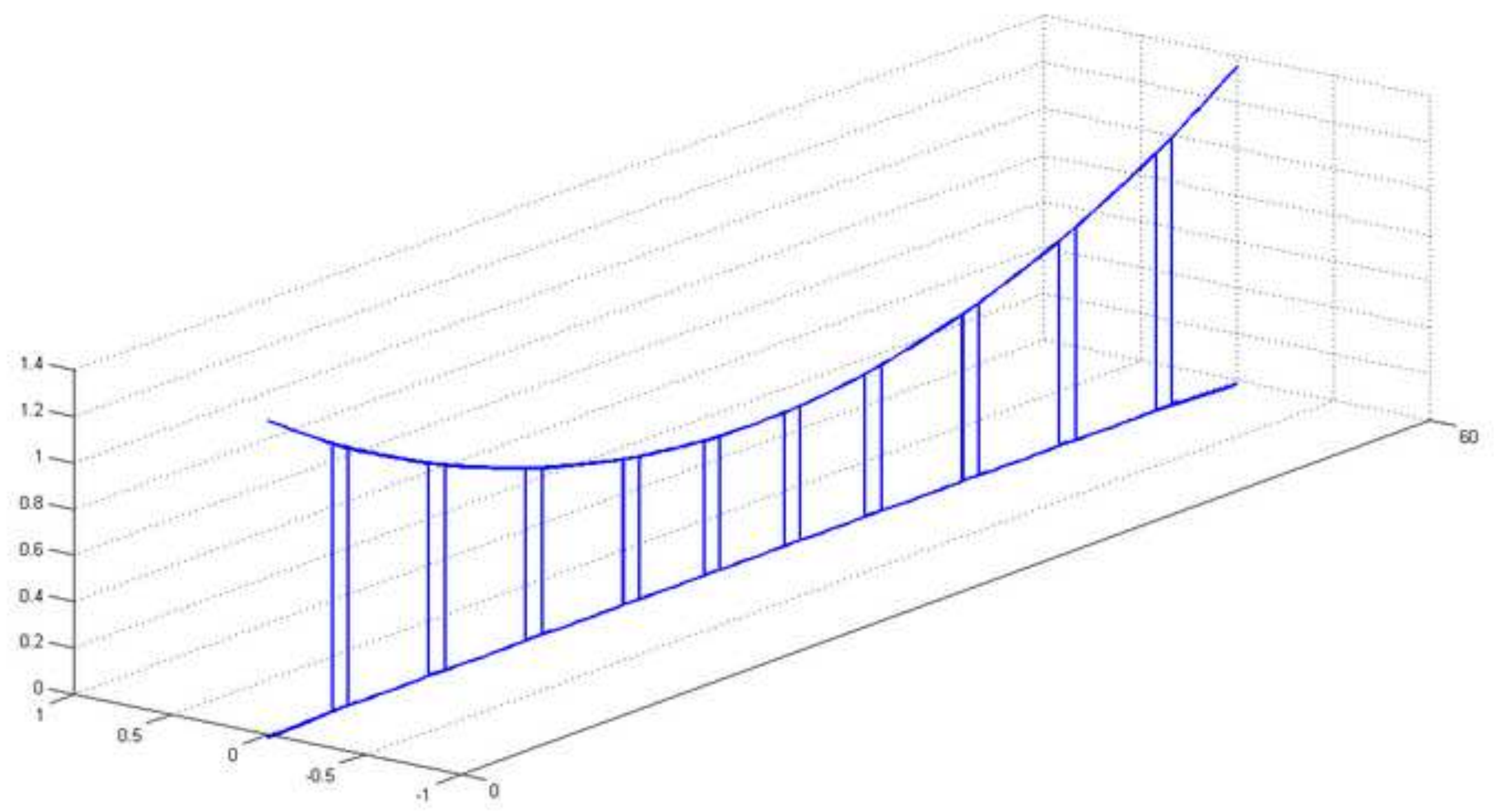




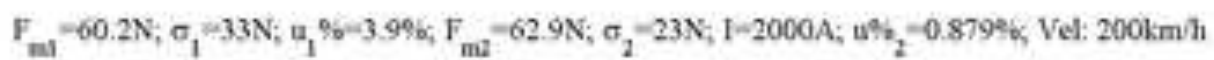
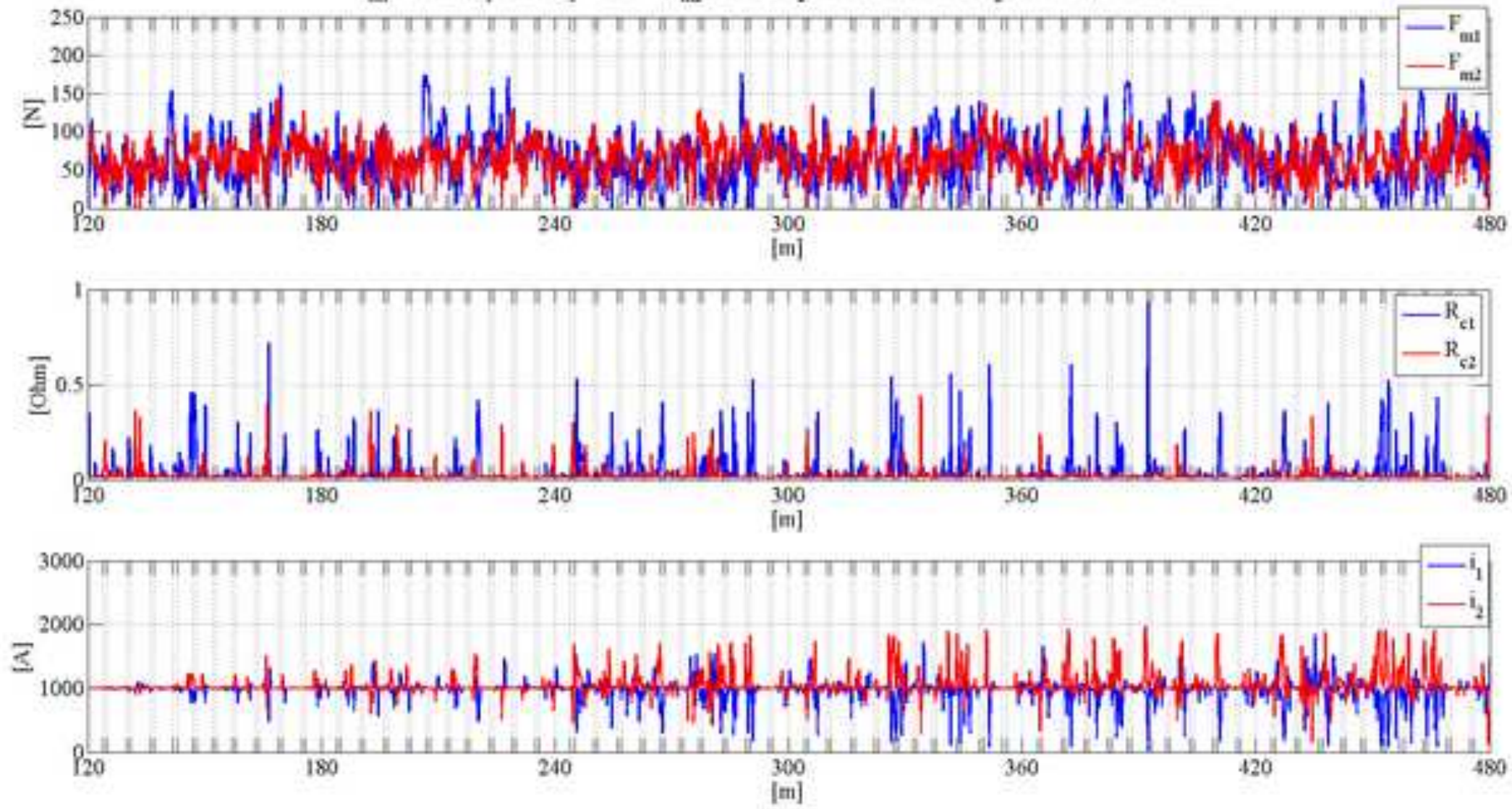


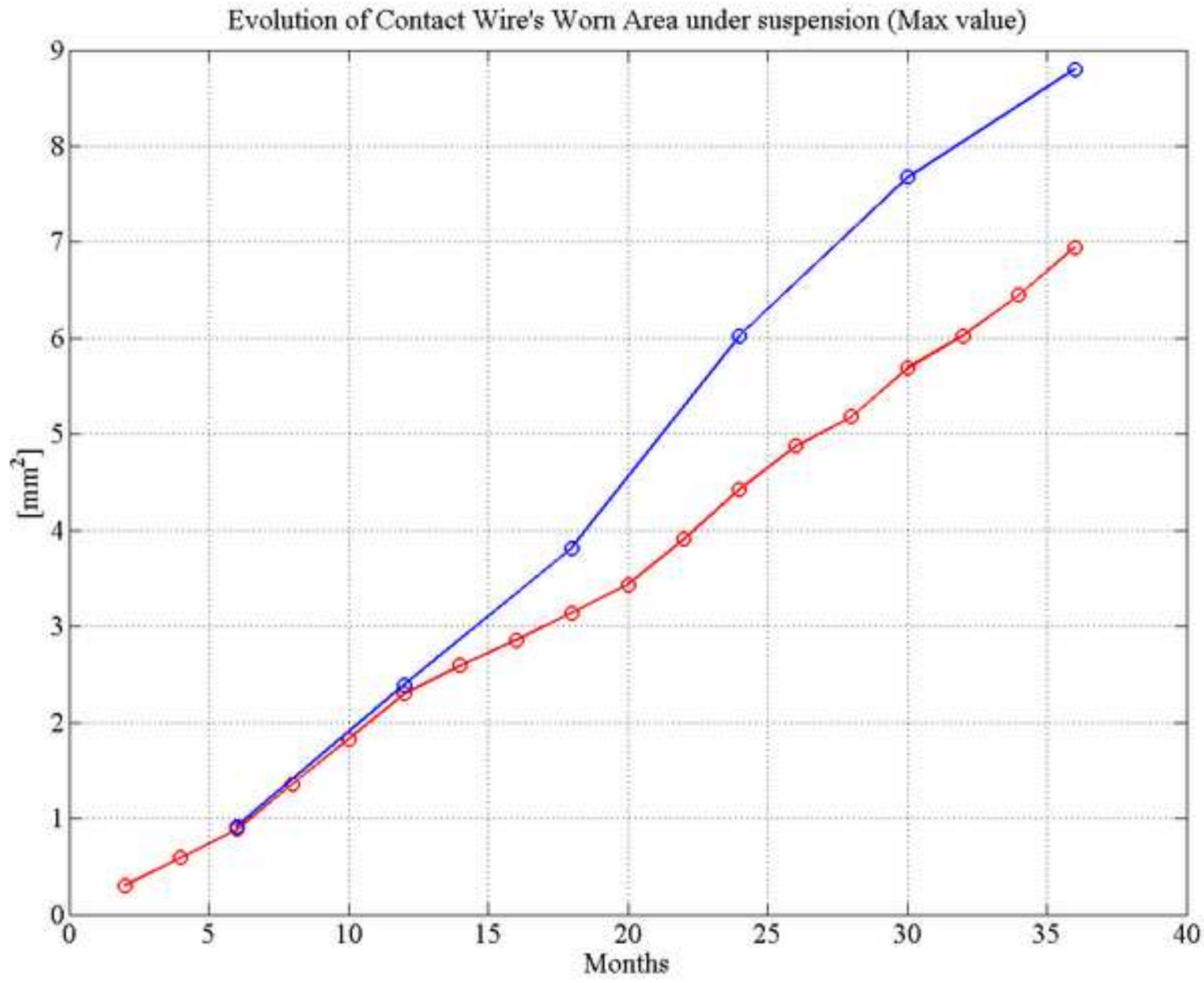




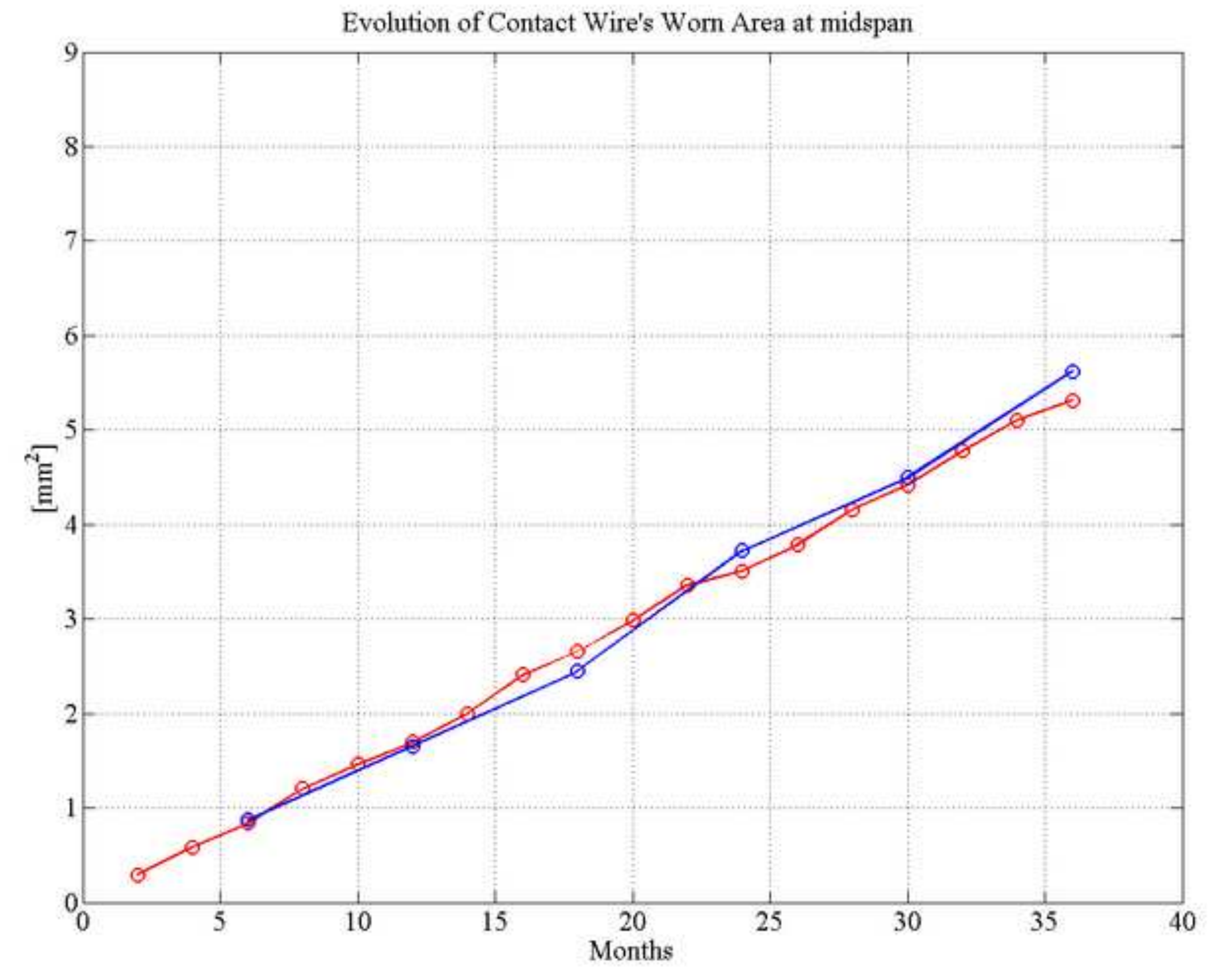

Evolution of Contact Wire's Worn Area at midspan 


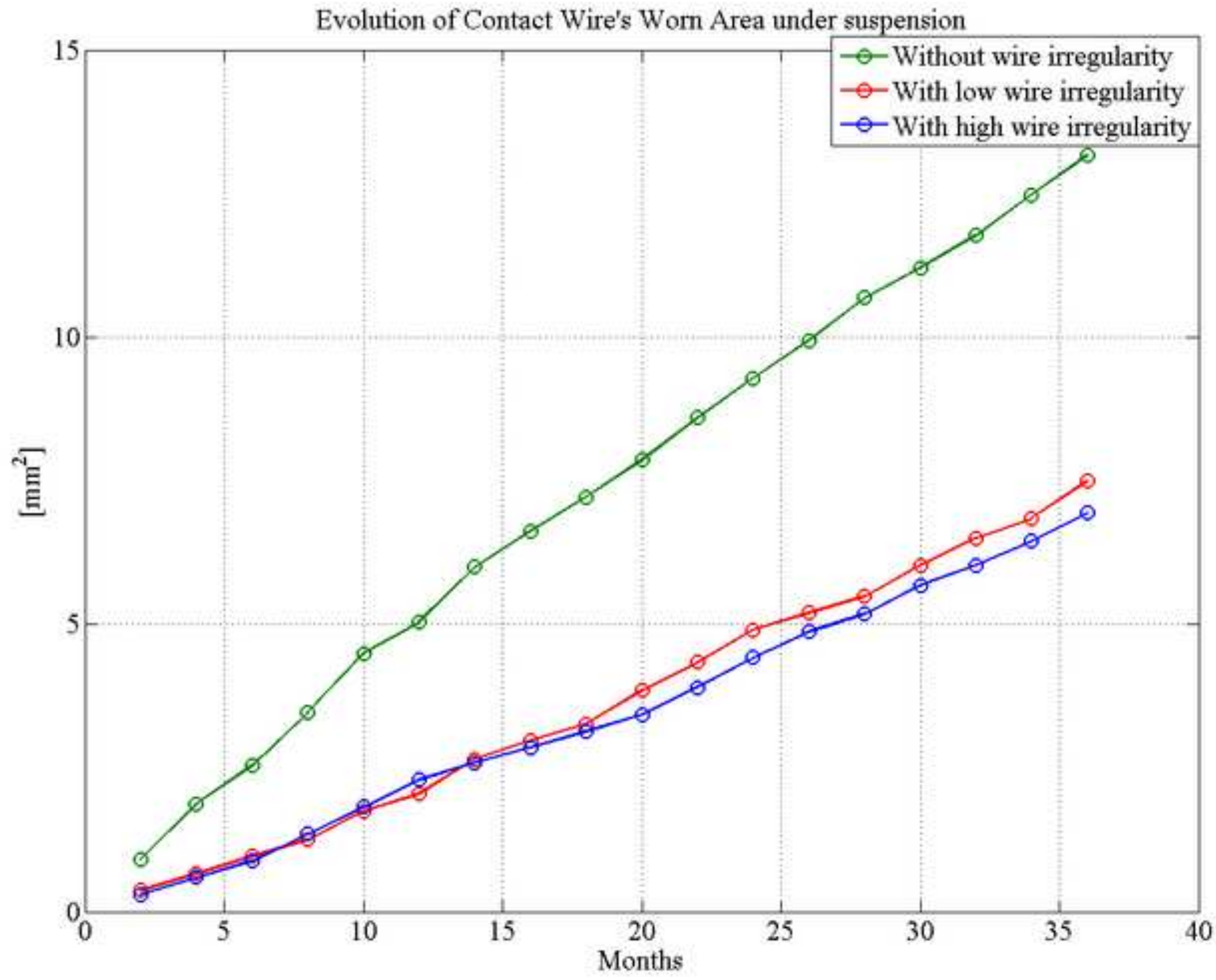




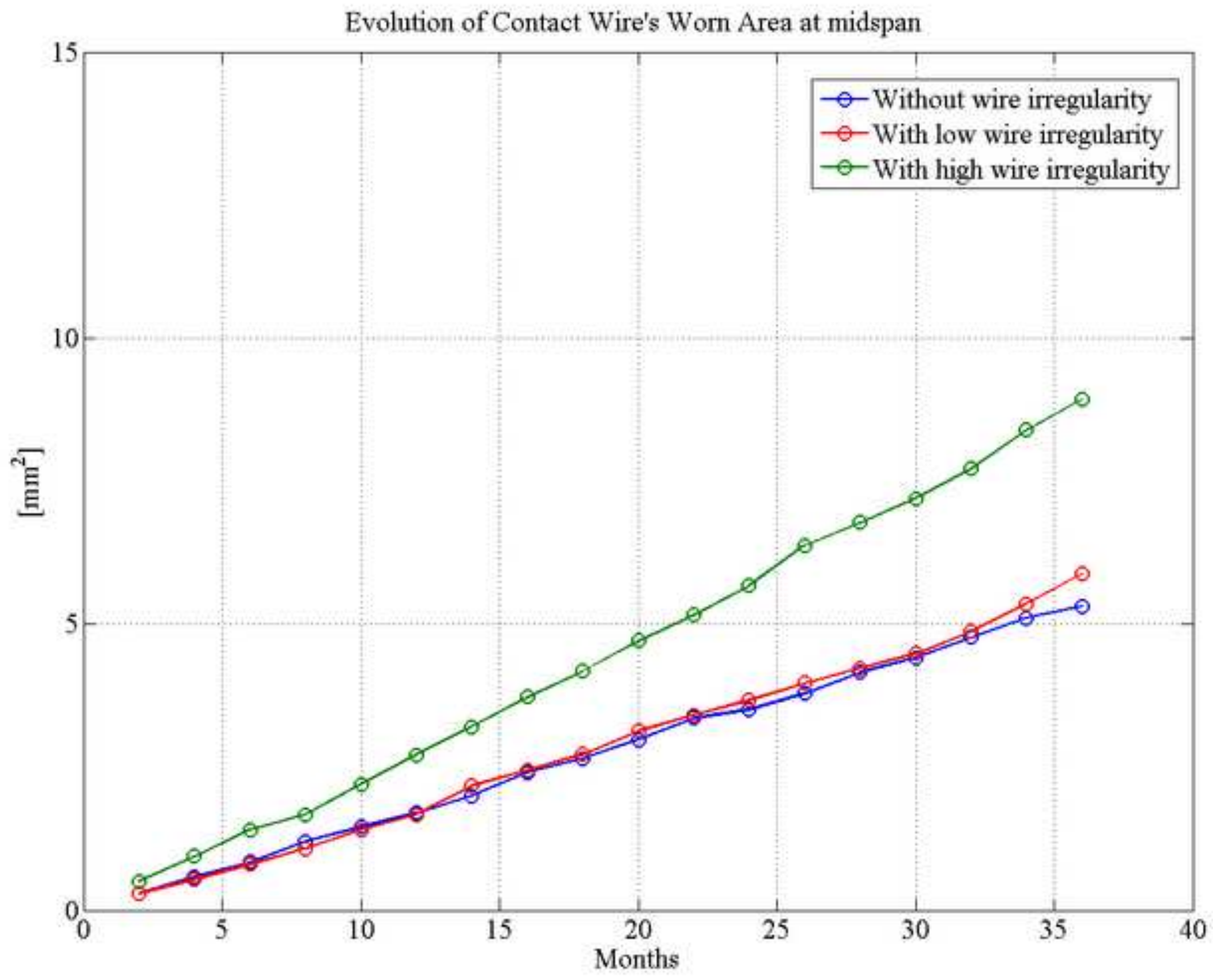




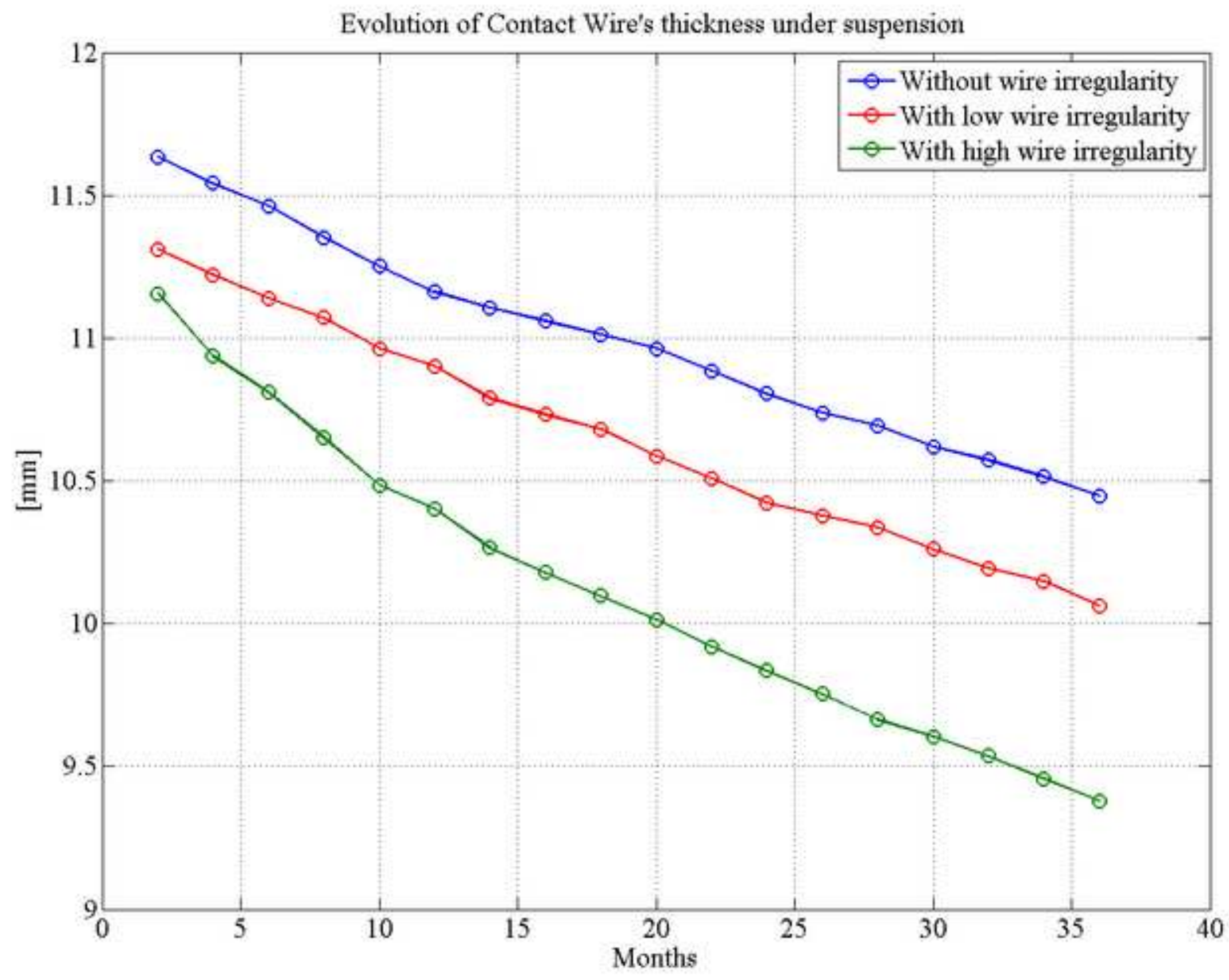




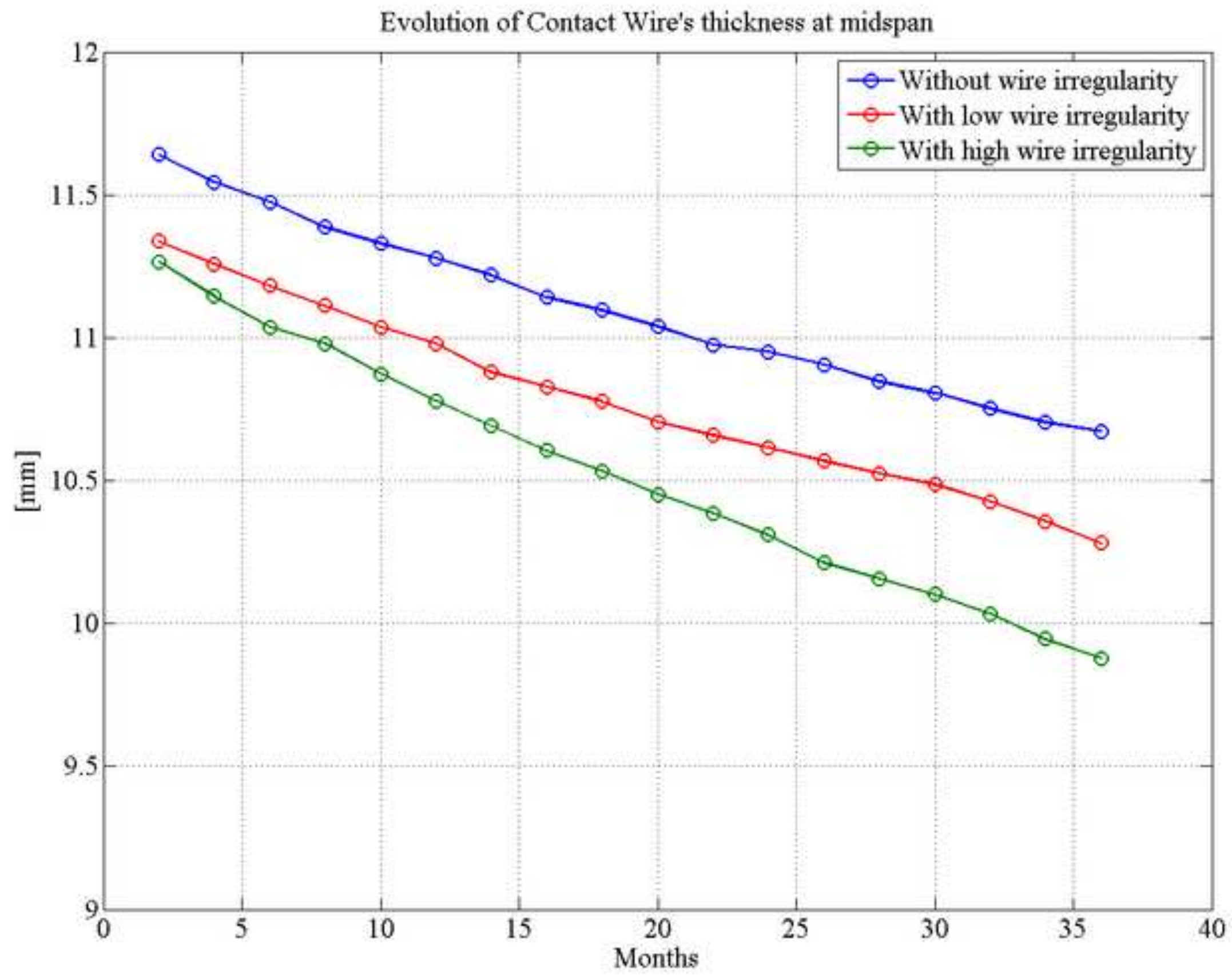


Table 1. The sequence of the wear tests.

\begin{tabular}{|c|c|c|c|}
\hline Test number & Test speed & Static preload & Electrical current (d.c.) \\
\hline 1 & \multirow{4}{*}{$160 \mathrm{~km} / \mathrm{h}$} & \multirow[t]{2}{*}{$60 \mathrm{~N}$} & $300 \mathrm{~A}$ \\
\hline 2 & & & $750 \mathrm{~A}$ \\
\hline 3 & & \multirow{4}{*}{$90 \mathrm{~N}$} & $300 \mathrm{~A}$ \\
\hline 4 & & & $750 \mathrm{~A}$ \\
\hline 5 & \multirow{4}{*}{$200 \mathrm{~km} / \mathrm{h}$} & & \multirow{4}{*}{$1000 \mathrm{~A}$} \\
\hline 6 & & & \\
\hline 7 & & $90 \mathrm{~N}+$ dynamics & \\
\hline 8 & & \multirow{9}{*}{$90 \mathrm{~N}$} & \\
\hline 9 & \multirow{8}{*}{$160 \mathrm{~km} / \mathrm{h}$} & & $300 \mathrm{~A}$ \\
\hline 10 & & & $500 \mathrm{~A}$ \\
\hline 11 & & & $750 \mathrm{~A}$ \\
\hline 12 & & & $1000 \mathrm{~A}$ \\
\hline 13 & & & $300 \mathrm{~A}$ \\
\hline 14 & & & $\mathbf{0 A}$ \\
\hline 15 & & & $100 \mathrm{~A}$ \\
\hline 16 & & & $200 \mathrm{~A}$ \\
\hline
\end{tabular}

Table 2. Variables and parameters present in the wear model of contact wire

\begin{tabular}{|l|l|c|}
\hline Symbol & Meaning & Cu-ETP \\
\hline$F_{m}$ & Mean value of contact force [N] & - \\
\hline$k_{l}$ & Weight of mechanical contribution to the whole wear & 22.4 \\
\hline$k_{2}$ & Weight of electrical contribution to the whole wear & 10.3 \\
\hline$k_{3}$ & Weight of contribution due to electrical arcs to the whole wear & 0.4 \\
\hline$\alpha$ & $\begin{array}{l}\text { Coefficient of dependence for the mechanical contribution on } \\
\text { the electrical current }\end{array}$ & 4.5 \\
\hline$\beta$ & $\begin{array}{l}\text { Coefficient of non-linear dependence of mechanical } \\
\text { contribution on the mean value of contact force }\end{array}$ & 1.8 \\
\hline$I_{0}$ & Reference value of electrical current [A] & 500 \\
\hline$I_{c}$ & Nominal electrical current during tests [A] & - \\
\hline$F_{0}$ & Reference value of contact force [N] & 90 \\
\hline$H$ & Hardness of material [N/mm $\left.{ }^{2}\right]$ & 700 \\
\hline$R_{c}$ & Electrical contact resistance between strip and wire (eq.3) [S] & - \\
\hline$V$ & Sliding speed in the tests [m/s] & - \\
\hline$V_{0}$ & Reference value of sliding speed [m/s] & 44.4 \\
\hline$u$ & Decimal fraction value of percentage of contact loss & - \\
\hline$V_{a}$ & Electrical arc voltage [V] & 205 \\
\hline$H_{m}$ & Latent heat of fusion for copper [kJ/kg] & 8940 \\
\hline$\rho$ & Density of copper [kg/m $\left.{ }^{3}\right]$ & \\
\hline
\end{tabular}

